\title{
Toward a better understanding of phase transformations in additive manufacturing of Alloy 718
}

\author{
Chamara Kumara ${ }^{a}$, Arun Ramanathan Balachandramurthi ${ }^{\mathrm{a}}$, Sneha Goel ${ }^{\mathrm{a}}$, Fabian Hanning a, \\ Johan Moverare ${ }^{a, b}$
}

${ }^{a}$ Division of Subtractive and Additive Manufacturing Processes, Department of Engineering Science, University West, 46186 Trollhättan, Sweden

${ }^{\mathrm{b}}$ Division of Engineering Materials, Department of Management and Engineering, Linköping University, SE-58183 Linköping, Sweden

\section{A R T I C L E I N F O}

\section{Keywords:}

Additive Manufacturing

Alloy 718

Phase transformation

Modelling

\begin{abstract}
A B S T R A C T
This paper presents a discussion on the phase-transformation aspects of additively manufactured Alloy 718 during the additive manufacturing (AM) process and subsequent commonly used post-heat treatments. To this end, fundamental theoretical principles, thermodynamic and kinetics modeling, and existing literature data are employed. Two different AM processes, namely, laser-directed energy deposition and electron-beam powder-bed fusion are considered. The general aspects of phase formation during solidification and solid state in Alloy 718 are first examined, followed by a detailed discussion on phase transformations during the two processes and subsequent standard post heat-treatments. The effect of cooling rates, thermal gradients, and thermal cycling on the phase transformation in Alloy 718 during the AM processes are considered. Special attention is given to illustrate how the segregated composition during the solidification could affect the phase transformations in the Alloy 718. The information provided in this study will contribute to a better understanding of the overall process-structure-property relationship in the AM of Alloy 718718.
\end{abstract}

\section{Introduction}

In recent years, compared with conventional manufacturing methods, additive manufacturing (AM) of nickel-based super Alloy $718 \mathrm{~s}$ has attracted considerable attention in aerospace and power generation applications [1]. In AM, a certain part is manufactured using a layer-bylayer approach using a 3D-digital model of the part. An important feature of this process is that it allows the production of complex, near-netshape objects (even through generative design), with minimal material waste. Furthermore, it enables part integration, thus reducing the number of assemblies and sub-assemblies required in the fabrication process. In addition, it allows manufacturing on demand, thereby reducing the need for a large inventory of spare parts. For these reasons, AM is considered a suitable manufacturing method for nickel-based super Alloy 718 components for aerospace and power-generation applications [2,3].

However, certain challenges should be overcome before AM could be used more effectively in aerospace and power-generation applications. One such challenge is to obtain the appropriate microstructure that provides the desired mechanical performance to the AM component. During the layer-by-layer deposition process, the material undergoes melting, solidification, and thermal cycling. This induces a liquid-to-solid phase transformation, as well as solid-state transformations. Therefore, the asbuilt microstructure of the component often leads to a heterogeneous microstructure with heterogeneous mechanical properties on a macroscopic length scale [1]. To overcome this, the common practice is to use suitable post-heat treatment (HT) protocols, with or without hot iso- static pressing (HIP), for the as-built part. These HTs further change the microstructure according to its composition segregation level, phases, and grain structure (morphology and texture). Therefore, to achieve the desired properties, it is necessary to understand the phase transformations during the formation of the as-built microstructure and under different HTs before the appropriate optimization is performed.

This study focuses on understanding the phase transformation of additively manufactured Alloy 718. Specifically, we use fundamental theoretical principles, thermodynamic and kinetics modeling, and existing literature data to explain the observed phase changes during the AM and post-HT of Alloy 718. Two different AM processes, namely, laserdirected energy deposition (L-DED) and electron-beam powder-bed fusion (EB-PBF) are considered. General aspects of the phase formation in Alloy 718 are first examined, followed by a discussion on the phase transformations during the two processes and subsequent HTs.

\section{Alloy 718}

Alloy 718 is a nickel-iron-based super Alloy 718. It has been extensively used in rocket motors, aircraft engines, nuclear reactors, and pumps [4]. The main reasons for its success are its relatively low cost and good mechanical as well as corrosion properties at low and intermediate temperatures $[5,6]$. However, its use in load-bearing components for elevated-temperature applications is limited to $650{ }^{\circ} \mathrm{C}$ owing to the strength loss beyond this temperature [7]. The composition of Alloy 718 is complex and involves several Alloy 718 ing elements, 


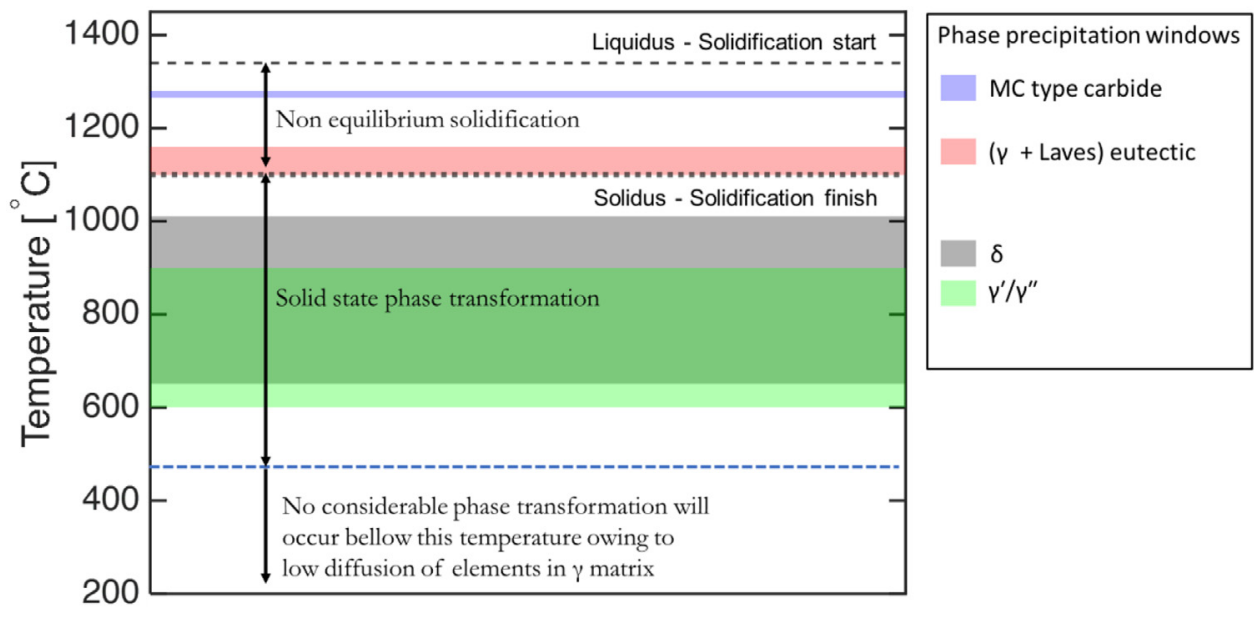

Fig. 1. Phase precipitation windows $([6,9,12])$ in Alloy 718during non-equilibrium solidification and in solid-state transformation. which are added to obtain the desired microstructure and properties. The nominal composition ranges for the Alloy 718 (according to the ASTM standard), their effect on the microstructure and crystal structure information of the commonly observed phases in Alloy 718 can be found in reference [8]. The Alloy 718 microstructure is primarily dominated by a face-centered cubic (FCC) $\gamma$ matrix, wherein precipitates such as $\gamma^{\prime} / \gamma^{\prime \prime}$ (strengthening phases), $\delta$, Laves, MC carbides, and nitrides can be found [9]. The $\delta$ phase is the equilibrium phase of the metastable $\gamma^{\prime \prime}$. The exact microstructure (phase composition, phase distribution, morphology, and volume fraction) of this Alloy 718 is mainly governed by the primary manufacturing technology and successive post-HT conditions. Fig. 1 shows the reported phase precipitation windows for Alloy 718. It can be seen that there is an overlap between the $\delta$ and $\gamma^{\prime} / \gamma^{\prime \prime}$ precipitation windows. Although $\delta$ is thermodynamically more stable than $\gamma^{\prime \prime}, \delta$ precipitation up to $\sim 900^{\circ} \mathrm{C}$ is always preceded by $\gamma^{\prime \prime}$ precipitation $[10,11]$.

\subsection{Non-equilibrium solidification}

During solidification processes, such as casting, welding, and AM, Alloy 718 tends to form a dendritic/cellular microstructure [9,13-15], the length scale of which varies according to the solidification conditions $[15,16]$. Knorovsky et al. [6] and Antonsson et al. [12] experimentally investigated the solidification sequence for Alloy 718. As temperature drops in the liquid (L) melt, the $\mathrm{L} \rightarrow \mathrm{TiN}$ transformation first occurs above the liquidus temperature. The resulting TiN particles occasionally act as nucleation sites for carbide precipitation at a later stage in the solidification [12]. However in the context of AM, TiN can also come via the feedstock material and could remain unmelt due to their higher melting point $\left(2930^{\circ} \mathrm{C}\right)$ [17].

When the temperature drops below liquidus, the solidification of the primary $\gamma$ phase takes place. During the solidification of the $\gamma$ matrix, segregation of Alloy 718 ing elements is typically observed [9]. This is because the solubility of the Alloy 718 ing elements in the matrix phase is different from that in the liquid. Elements such as Nb, Mo, and Ti, which have a low solubility limit in the matrix, tend to segregate to the liquid. Elements such as $\mathrm{Cr}, \mathrm{Fe}$, and $\mathrm{Al}$, which have a high solubility limit in the solid, tend to be trapped in the solid. This segregation alters the local thermodynamics of Alloy 718 and, hence, the driving force for phase formation. Therefore, phases such as Laves and $\mathrm{NbC}$ begin to form in the interdendritic liquid region during solidification. Owing to their low solubility in the matrix, $\mathrm{Nb}$ and $\mathrm{C}$ are continuously rejected into the liquid. As the matrix grows, the $\mathrm{Nb}$ and $\mathrm{C}$ compositions in the liquid reach a level that enables NbC formation. This reaction consumes $\mathrm{Nb}$ and the majority of $\mathrm{C}$ in the remaining liquid, shifting the remaining liquid composition back to a lower level. As $\gamma$ grows further, the segregation of $\mathrm{Nb}$ in the remaining liquid prompts another eutectic reaction $\mathrm{L} \rightarrow$ $\gamma+$ Laves, which terminates the solidification process. This is referred to as non-equilibrium solidification (Fig. 1). In the context of AM of Alloy 718 , the formed primary carbides and nitrides during non-equilibrium solidification do not change (in terms of size and distribution) noticeably at low temperatures owing to their stability at these temperatures. Therefore, in this study, the focus is on understanding the transformation of the $\gamma^{\prime} / \gamma^{\prime \prime}, \delta$, and Laves phases.

\subsection{Effect of solidification conditions on non-equilibrium solidification}

The partitioning of the elements and the level of segregation depend on the solidification conditions of the process, and it affects the formation of the secondary phases [12] during non-equilibrium solidification.

Antonsson et al. [12] studied the effect of the cooling rate (from $2.5 \times 10^{-1}$ to $2 \times 10^{4} \mathrm{C} / \mathrm{s}$ ) on the solidification of Alloy 718. During the rapid solidification that occurs at higher cooling rates $\left(>10^{4} \mathrm{C} / \mathrm{s}\right)$, it was observed that the interdendritic region contains less $\mathrm{Nb}$, and Laves phases are not present. Owing to the rapid solidification, the solutes become trapped in the moving solid/liquid interface because of the incomplete solute partitioning [18]. This results in less Nb segregation to the interdendritic liquid and hence insufficient concentration for Lavesphase formation. In contrast, during slower solidification (similar to the conditions in traditional casting), the interdendritic region was observed to have more dominant $\mathrm{Nb}$ and Laves phases.

However, in laser-beam powder-bed fusion (LB-PBF) of Alloy 718, Laves-phase formation is observed under non-equilibrium solidification conditions $[19,20]$, even though the reported cooling rates during the solidification of the melt pool are in the order of $10^{5 \circ} \mathrm{C} / \mathrm{s}[21,22]$. This contradicts the observation made by Antonsson et al., highlighting the fact that one cannot simply use the cooling rate alone as a criterion to describe whether the solidification process would result in Laves-phase formation; rather, one should also consider the solid-liquid interface velocity, thermal gradients, and undercooling conditions [18]. In the literature on the microstructure of additively manufactured Alloy 718, it has been demonstrated that Laves phases are present, implying that non-equilibrium solidification conditions occur [23-26]. This indicates that the solidification conditions during these processes do not trap a significant fraction of Alloy 718 ing elements in the moving solid/liquid interface, allowing the occurrence of element partition and hence Lavesphase formation (see Fig. 2).

The presence of Laves phases in the microstructure has a negative effect on the mechanical properties of Alloy 718(tensile strength, ductility, fatigue life, and fracture toughness) [29,30], owing to its brittle nature. Usually, liquation cracking is often observed in the microstructure when Laves phases are present in a long-chain morphology [30]. The low melting point of the Laves phase and the long-chain morphology will promote liquation cracking. As the Laves phase forms toward the 

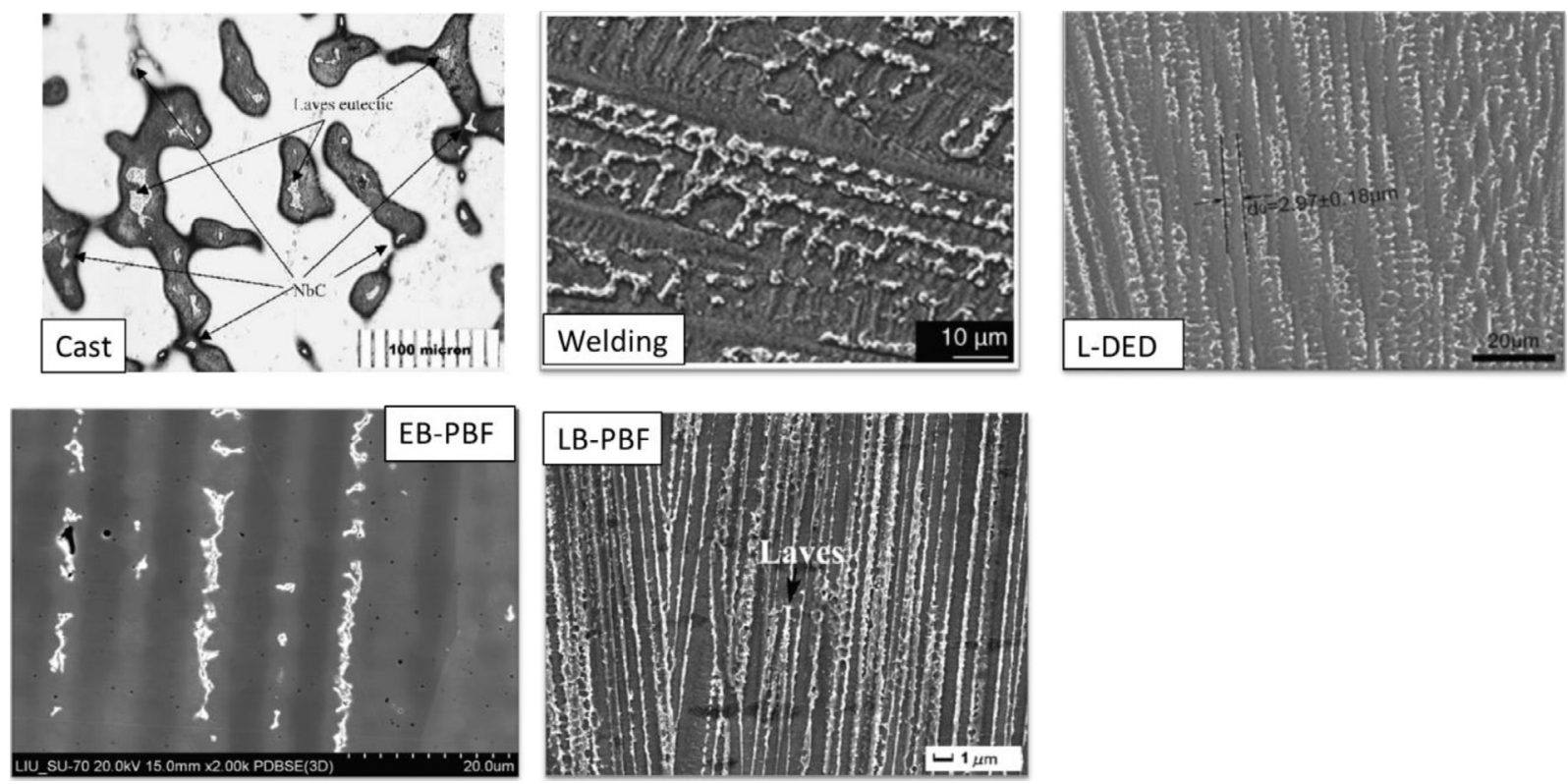

Fig. 2. Microstructures obtained from different process, exhibiting the formed Laves $+\mathrm{NbC}$ (white precipitates) at the end of non-equilibrium solidification. In L-DED, EB-PBF, and LB-PBF, the build direction is from bottom to top.

Source: Sources: cast [12], welding [27], L-DED [15], EB-PBF [14] and LB-BPF [28].

end of non-equilibrium solidification, its morphology is directly related to the morphology of the dendritic structure at that time. Therefore, by changing the dendrite morphology during the solidification process, the morphology of the Laves phase can be changed and potentially affect the propensity for liquation cracking.

It is well known in the casting and welding community that the dendritic structure during the solidification process can be altered by changing the solidification conditions, that is, thermal gradient $(G)$, cooling rate $(\dot{T})$, and liquid-solid interface velocity $\left(R=\frac{\dot{T}}{G}\right)[31,32]$. This is true in the case of AM of Alloy 718 as well, where it can be achieved by changing the process parameters that directly affect the thermal conditions in the melt pool. Depending on these conditions, the resulting dendritic structure could have a columnar, equiaxed, or mixed morphology $[33,34]$.

The effect of the thermal gradient (from bottom to top in the domain) and cooling rate on the dendritic structure of Alloy 718 is shown in Fig. 3. These results were obtained from multiphase-field simulations of Alloy 718 under different thermal conditions. Information about this modelling is presented in Appendix A.

It can be seen in Fig. 3 (a) that the dendritic structure during solidification changes with the cooling rate and thermal gradient. This ultimately affects the size and morphology of the Laves-phase particles, as shown in Fig. 3 (b). At low cooling rates, the dendritic structure is coarser. Therefore, the resultant Laves-phase structure is also coarse, and its morphology tends to the long-chain form, which has been demonstrated to have a negative effect on the microstructure, as it promotes liquation cracking [30]. As Laves phases form during the final solidification stage, they begin to melt around the eutectic-forming temperature when the temperature of the material is raised. If a Laves phase has a long-chain morphology, liquid can form along with this chain morphology at the reheating stage during thermal cycling above the eutectic-forming temperature. When combined with the tensile stresses generated at the reheating stage, this liquation can easily lead to cracking.

As the cooling rate increases, the amount of undercooling experienced by the liquid becomes higher for a given time. Higher undercooling results in higher excess free energy in the liquid, which is consumed by the liquid-solid interface that is created (though nucleation and/or growth). When the amount of excess free energy becomes large, more and more liquid-solid interfaces are created per unit area. Consequently, the resultant dendritic structure is finer on the length scale. In fine dendritic microstructures, the thickness and spacing of the primary and secondary dendrite arms become smaller. Therefore, toward the end of the solidification, the remaining liquid areas are trapped between these fine dendric structures. This results in fine and discrete Laves-phase particles at the end of the solidification. When the Laves phase distributes in the microstructure as discrete and fine particles, the propensity for hot-crack formation is reduced, as a continuous liquid film is difficult to generate. In addition, as the cooling rate increases, the resultant Laves-phase area fraction is reduced, as shown in Fig. 3 (c).

\subsection{Solid-state phase transformation after non-equilibrium solidification}

After non-equilibrium solidification, solid-state phase transformations take place as the temperature continues to fall. The main phases that can precipitate in the solid state are $\gamma^{\prime} / \gamma^{\prime \prime}$ and $\delta$. Immediately after non-equilibrium solidification, there exists a composition gradient from the dendrite core to the interdendritic region in the $\gamma$ matrix. Therefore, the local equilibrium conditions and driving forces for solid-state phase transformation change from the dendrite core to the interdendritic region $[24,35,36]$.

Fig. 4 shows a simulated Alloy 718 microstructure at the end of a non-equilibrium solidification [23] in the L-DED process and the segregated 1-D composition profiles along a line from the dendrite core to the interdendritic region. Reader is refered to [23] for details about the modelling work. In this simulation, Alloy 718 is modeled as a sevenelement system with Ni-Fe-Cr-Mo-Nb-Ti-Al. The most segregated elements are $\mathrm{Nb}$ and $\mathrm{Fe}$, whereas the least segregated are $\mathrm{Ti}$ and $\mathrm{Al}$. The generally accepted chemical composition formula for both $\gamma^{\prime \prime}$ and $\delta$ is $\mathrm{Ni}_{3} \mathrm{Nb}$ [4]. Therefore, the distribution of $\mathrm{Nb}$ has a profound effect on the distribution of $\gamma^{\prime \prime}$ and $\delta$. The generally accepted chemical formula for $\gamma$ ' is $\mathrm{Ni}_{3}(\mathrm{Al}, \mathrm{Ti})$ [4]. Thus, the distribution of $\mathrm{Al}$ and $\mathrm{Ti}$ affects the distribution of $\gamma^{\prime}$. These modeling results agree well with the experimental observations made by Sui et al. [4]. From the 1-D segregation profiles, the $\mathrm{Al}$ segregation level is quite low, indicating a relatively homogenous distribution of $\mathrm{Al}$ in the microstructure. However, this is not the case for 

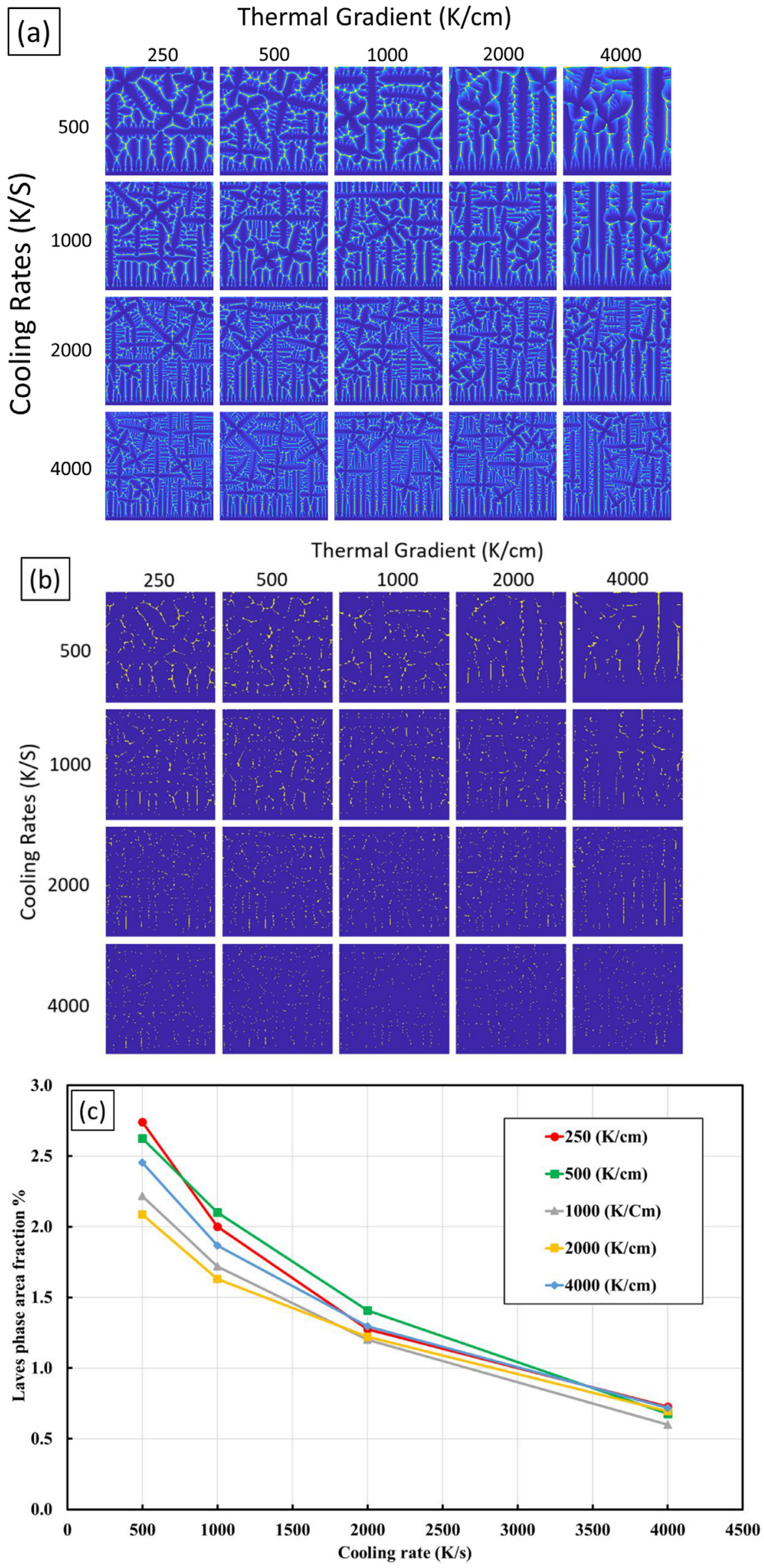

Fig. 3. (a) Variation in the dendrite structure under different solidification conditions.

(b) Variation in the Laves-phase morphology under different solidification conditions.

(c) Variation of Laves-phase area fraction under different solidification conditions.

Both (a) and (b) were taken at the end of nonequilibrium solidification simulation described in Appendix A. Domain size is $80 \mu \mathrm{m} \times 80 \mu \mathrm{m}$. 

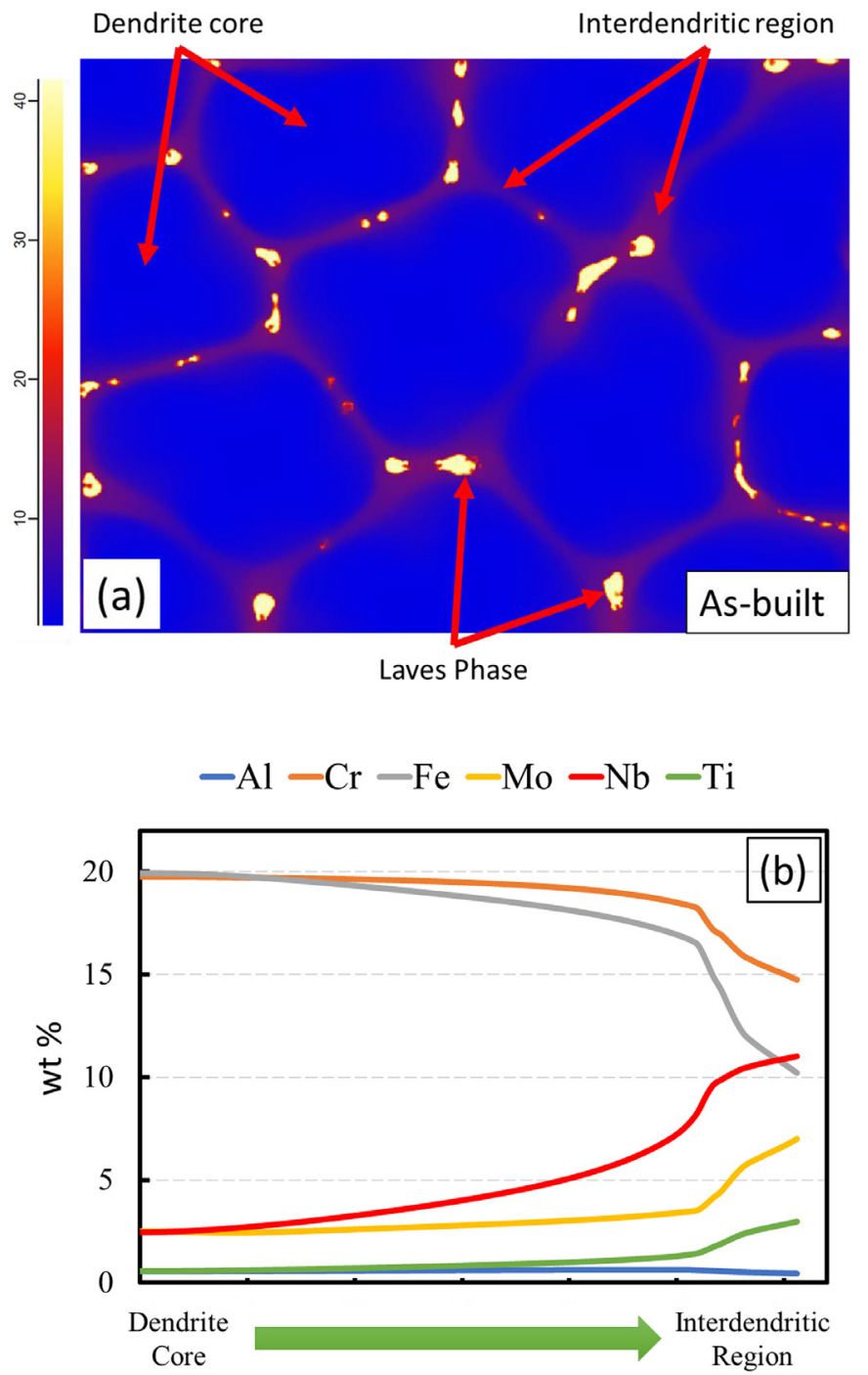

Fig. 4. (a) As-built microstructure at the end of non-equilibrium solidification simulation performed using MICRESS, domain size $25 \mu \mathrm{m} \times 20 \mu \mathrm{m}$. Scale shows the $\mathrm{Nb}$ distribution in $\mathrm{wt} \%$.

(b) 1D composition profiles extracted from a multiphase field simulation at the end of the non-equilibrium simulation.

Note: Simulation results were taken from a previous simulation work published in [23].

Ti; preferential segregation of Ti is clear, and thus its distribution could affect the distribution of $\gamma^{\prime}$. Nevertheless, as the segregation of $\mathrm{Nb}$ is higher than that of $\mathrm{Al}$ and $\mathrm{Ti}$, it can be expected that the variation in the distribution of $\gamma^{\prime \prime}$ is more pronounced than that of $\gamma^{\prime}$ in the matrix.

To gain insight into the effect of segregation on the local equilibrium conditions of Alloy 718, equilibrium volume fraction diagrams were generated using the JMatPro (JMatPro is a trademark of Sun Microsystems, Inc - ver10.2) software package considering the composition in the dendrite core and the interdendritic region in Fig. 4. For comparison, the equilibrium volume fraction related to the nominal composition of Alloy 718 was also generated, and the results are shown in Fig. 5. It can be clearly seen that segregation has a direct effect on the equilibrium conditions for $\gamma^{\prime} / \gamma^{\prime \prime}$ and $\delta$. Away from the dendrite core and close to the interdendritic region, there is an increase in the volume fraction for the $\gamma^{\prime} / \gamma^{\prime \prime}$ and $\delta$ phases; moreover, the equilibrium transformation temperature for the phases changes.
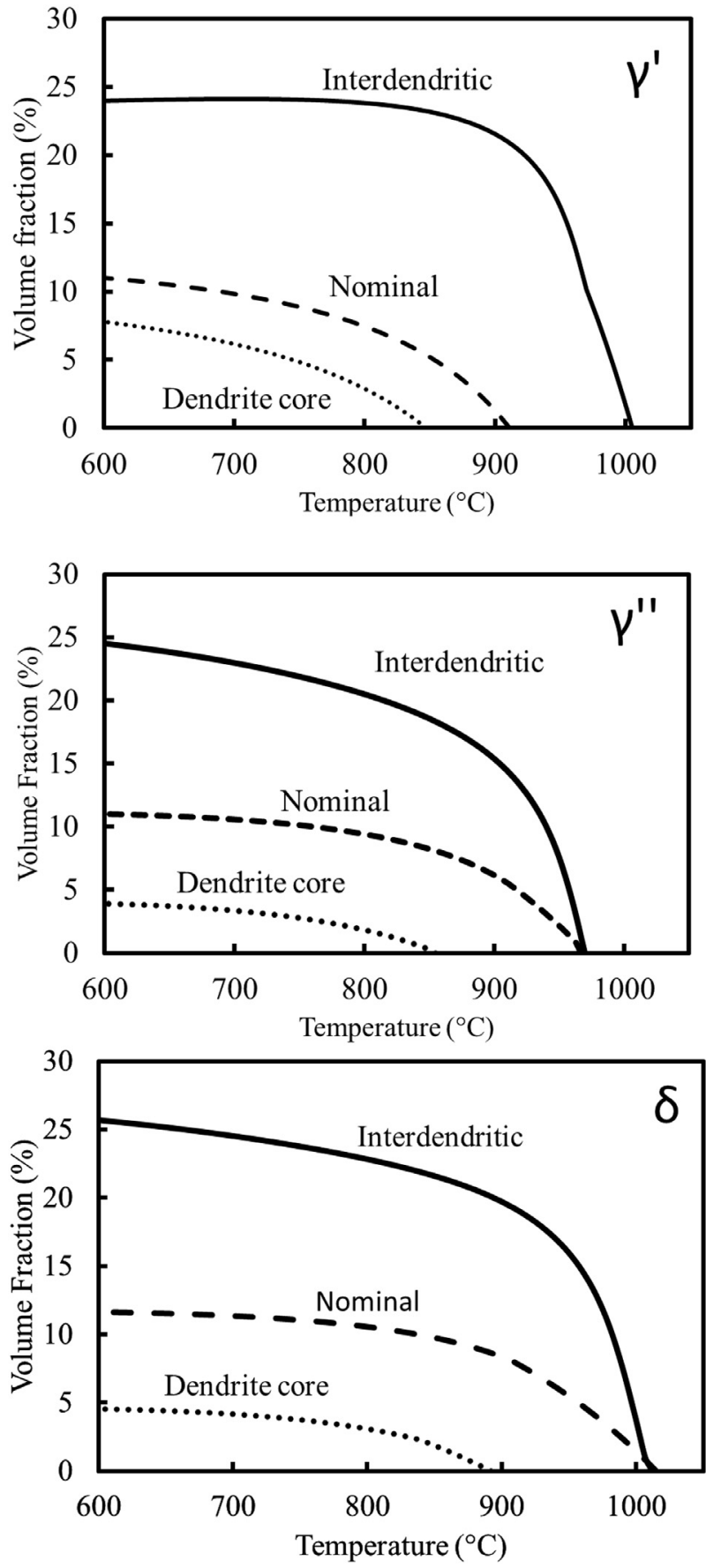

Fig. 5. Equilibrium volume fractions of $\gamma^{\prime}, \gamma^{\prime \prime}$, and $\delta$ predicted using JMatPro for nominal, interdendritic, and dendrite core composition. Composition for the interdendritic and dendrite core was taken from Fig. 4(b). In the calculation of $\gamma^{\prime \prime}, \delta$ was suspended.

\subsection{Effect of cooling rate on solid-state phase transformation after non-equilibrium solidification}

The solid-state phase transformation in Alloy 718 is a diffusioncontrolled process. That is, the phase transformation is affected by element diffusion. As the element diffusion coefficient in the $\gamma$ phase is lower than that in the liquid phase, the extent of solid-state phase transformation is influenced by the cooling rate of the process. In the case of slow cooling (as in traditional casting) shown in Fig. 6, the as-solidified material spends a relatively longer time in the precipitation windows of the $\gamma^{\prime} / \gamma^{\prime \prime}$ and $\delta$ phases. Therefore, there is sufficient time for phase nu- 


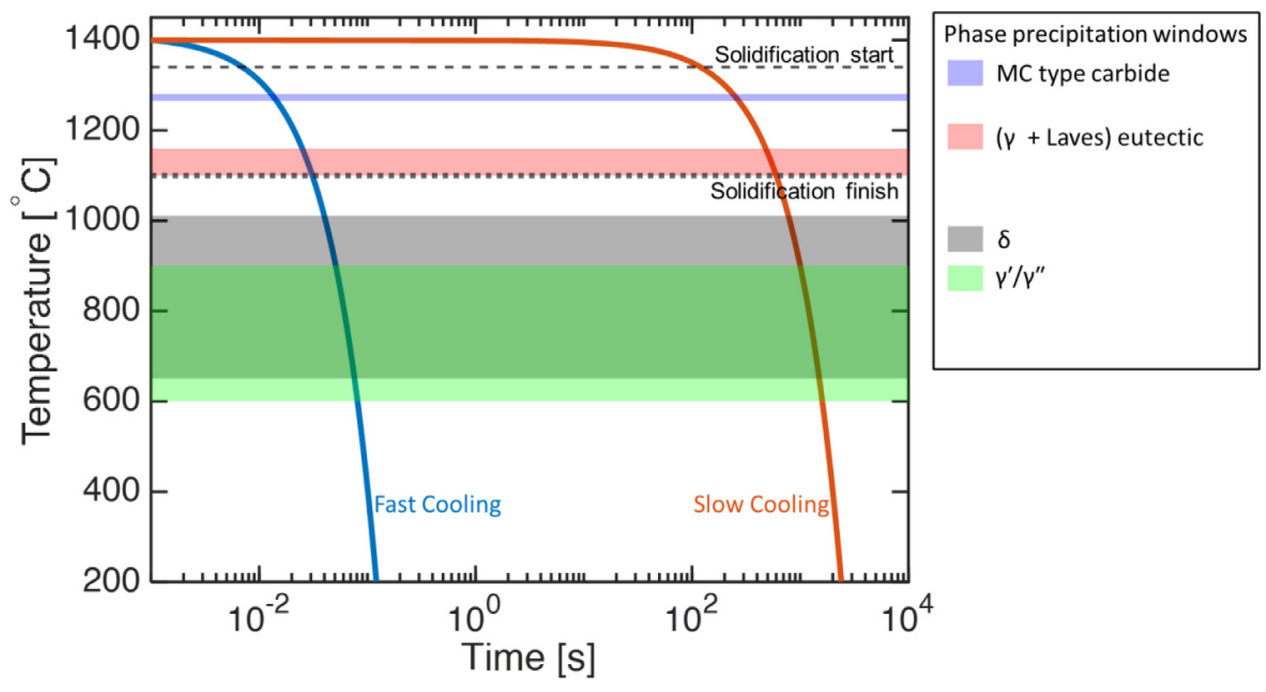

Fig. 6. Schematic representation of slow and fast cooling.
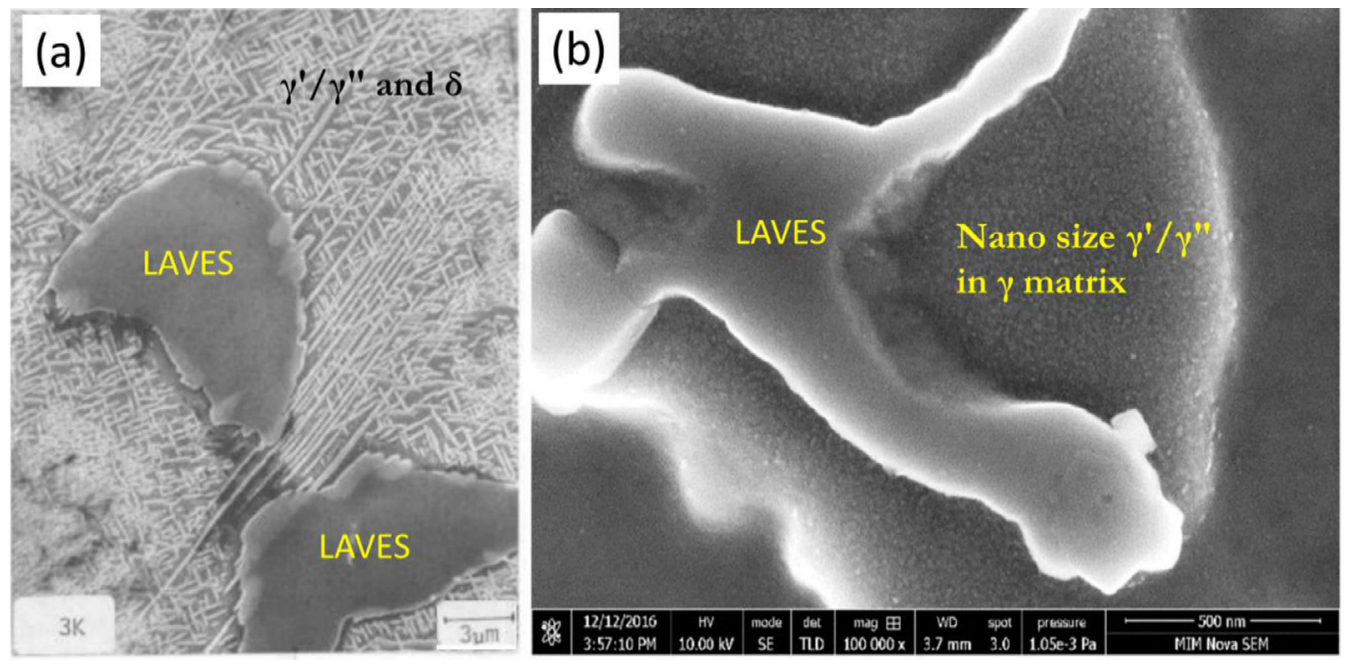

Fig. 7. (a) SEM image of the interdendritic area of an as-cast Alloy 718. $\gamma^{\prime} / \gamma^{\prime \prime}$ and $\delta$ phases have precipitated around the Laves. Taken from [9]. (b) Nano-SEM image of the interdendritic region of LMDED Alloy 718. $\gamma^{\prime} / \gamma^{\prime \prime}$ has precipitated around the Laves phase. Taken from [38].

cleation and growth. At the end of the slow cooling process, $\gamma^{\prime} / \gamma^{\prime \prime}$ and $\delta$ phases can be observed in the microstructure. These tend to nucleate and grow in size primarily in the segregated interdendritic regions (close to Laves phases that are also present), as in the case of cast Alloy 718(Fig. 7 (a)) [37]. The reason for this is similar to the explanation of the segregation affecting the equilibrium conditions and inducing phase transformation in Alloy 718. The size growth of these phases is also supported by the high element concentration in the interdendritic region. However, as the segregation of $\mathrm{Nb}$ is comparatively higher than that of $\mathrm{Al}$ and $\mathrm{Ti}$, the growth of the $\gamma^{\prime \prime}$ and $\delta$ phases in the interdendritic region is expected to be higher compared to that of the $\gamma^{\prime}$ phase.

In the case of rapid cooling (as in AM), as shown in Fig. 6, the assolidified material spends a small amount time in the precipitations windows of $\gamma^{\prime} / \gamma^{\prime \prime}$ and $\delta$. Therefore, these phases only have a short period time for nucleation and growth in the microstructure. The precipitation, in this case, is likely to occur in interdendritic regions owing to the compositional segregation. However, the size of the $\gamma^{\prime} / \gamma^{\prime \prime}$ and $\delta$ phases is quite small compared with that of the cast material upon initial cooling to temperatures below $500{ }^{\circ} \mathrm{C}$. In an experimental study by Segerstark et al. [38], where transmission electron microscopy was used, nano-size precipitation of $\gamma^{\prime} / \gamma^{\prime \prime}$ was observed in the interdendritic region of the final layer of material that had been deposited through laser metal powder directed energy deposition. However, no $\delta$ phase was observed in the as-built microstructure. It is interesting to note that the $\delta$ phase precipitates in the interdendritic region when the process has slow cooling (as in casting), but not when the process has faster cooling (as in AM). The time that the microstructure spent in the $\delta$ precipitation window in $\mathrm{AM}$ is shorter than that during casting (Fig. 5). Thus, there is more time for the $\delta$ phase to grow in casting.

This implies that the final microstructure of Alloy 718 is influenced by the cooling rate of the process, and therefore different microstructures resulting from different process conditions will respond differently when subjected to further HTs.

\section{Laser-directed energy deposition}

Laser-directed energy deposition is a directed energy deposition AM process, where laser energy is directed and focused into a narrow region in the substrate/previously deposited layer, melting both the substrate/previously deposited layer and the feedstock material that is being deposited. The latter can be in the form of either powder or wire. This method is widely used to repair corroded and worn gas-turbine components because it involves minimal distortion and dilution [36]. Moreover, it is used to construct small components or add features to, for instance, cast components, thus adding complexity to products [2]. Thereby, the cost of components with complex features can be reduced. 


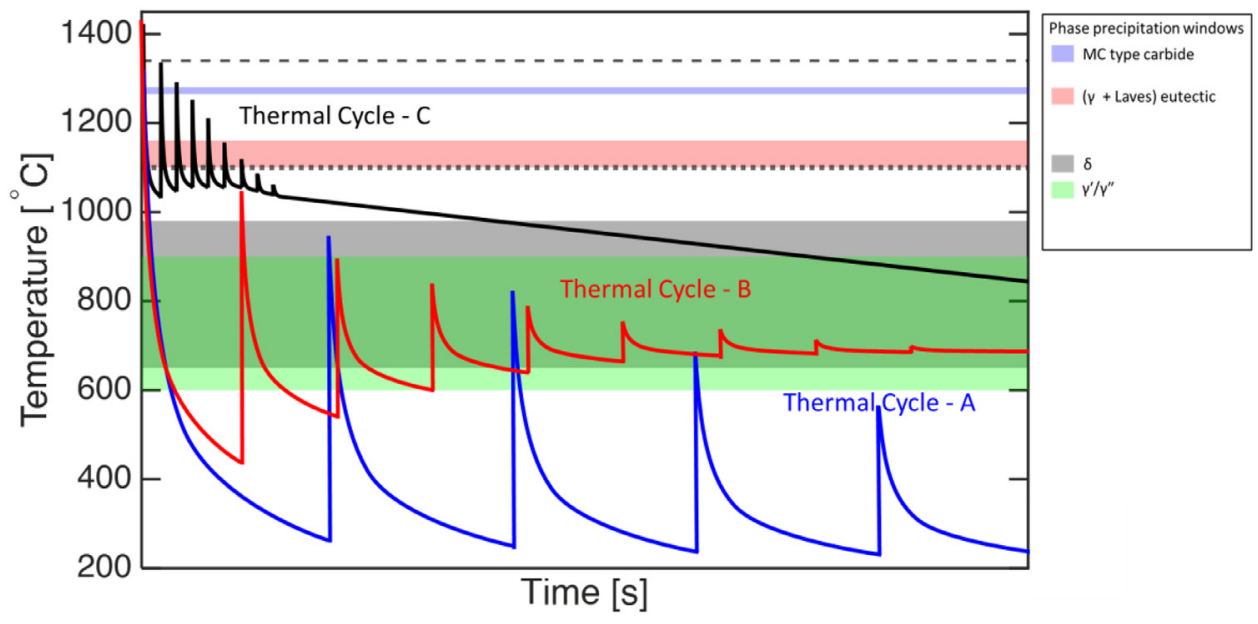

Fig. 8. Schematic representation of different the thermal cycles in L-DED process.

Note that the start of the thermal cycles shows the final solidification. That means thermal cycles that cause the first melting and further remelting are not shown in this schematic.

\subsection{Phase formation during $L-D E D$ of Alloy 718}

Owing to the inherent nature of L-DED, the material undergoes multiple thermal cycles when adjacent tracks/beads are deposited. Depending on the nature of these thermal cycles, phase transformations occur, resulting in different microstructures that contain different phases and phase fractions.

In L-DED, during the solidification of Alloy 718, phase transformations occur as described in Section 2. After the solidification of the material, the underlying microstructure has a segregated dendritic microstructure with interdendritic Laves and $\mathrm{NbC}$ phases [23]. Thereafter, this microstructure undergoes changes during the ensuing thermal cycles owing to the subsequent material deposition. For a better understanding of the solid-state phase transformation during this thermal cycling, we consider the thermal cycles shown in Fig. 8. These thermal cycles resemble the thermal conditions that are typically encountered during material deposition.

In thermal cycle $\mathrm{A}$, there is sufficient time between the deposition of successive layers so that the material addition does not cause a rise in the global temperature of the deposited material. This type of thermal cycling resembles the thermal cycles reported in $[23,38,39]$. In this case, even though the temperature goes through the precipitation windows of $\gamma^{\prime} / \gamma^{\prime \prime}$ and $\delta$ during the thermal cycling, no significant phase transformation is observed. This is because the time that the material spends in these precipitation windows is quite short. Thus, diffusion and hence phase growth cannot occur. In addition, this type of thermal cycling does not significantly affect the Laves phases formed during the first cycle. This has been experimentally demonstrated in [23]. However, the situation may be different under such thermal conditions as those in thermal cycle B.

Thermal cycle B illustrates a case where the deposition of multiple layers is performed without sufficient inter-pass waiting time to cool down the previously deposited material to a temperature close to room temperature. In these conditions, the global temperature of the deposited material rises owing to heat accumulation. The experimentally measured temperature profile in Tian et al. [36] resembles such a condition. This rise in the global temperature has an effect similar to that of an HT, both to the deposited and to the base material, if the temperature is above $\sim 600^{\circ} \mathrm{C}$. If the thermal conditions during processing resemble those in thermal cycle $\mathrm{B}$, then this may be thought of as in situ ageing HT for the previously deposited material. Therefore, with time, $\gamma^{\prime} / \gamma^{\prime \prime}$ begins to precipitate in the material, and this precipitation is influenced by the local compositional segregation in the microstructure. It should be noted that the rise in the global temperature $\left(>\sim 600^{\circ} \mathrm{C}\right)$ also affects the substrate material. The amount of the $\gamma^{\prime} / \gamma^{\prime \prime}$ precipitate in the interdendritic region is larger compared with that in the dendrite core owing to the higher equilibrium volume fraction expected for local variation in the chemical composition. In addition, these precipitates grow in size with the time that the material spends in the in situ ageing. This generates a gradient of $\gamma^{\prime} / \gamma^{\prime \prime}$ precipitates from the interdendritic region to the dendrite core, as well as from the bottom to the top of the deposited sample. Therefore, there will be a hardness gradient in the material from top to bottom, which was experimentally confirmed by Tian et al. [36] (Figs. 4 and 7 in their paper).

Thermal cycle $\mathrm{C}$ is similar to thermal cycle $\mathrm{B}$, but the heat accumulation is greater; therefore, the rise in the global temperature is higher than that in thermal cycle B. Such a thermal condition was reported by Z. Li et al. [40] during high-deposition-rate L-DED of Alloy 718. In this thermal cycle, the global temperature of the material first rises to a higher value $\left(>1000^{\circ} \mathrm{C}\right)$ and then drops gradually during the deposition process owing to heat conduction. When the temperature drops, it passes both the $\gamma^{\prime} / \gamma^{\prime \prime}$ and $\delta$ precipitation windows. Thus, in this case, $\gamma^{\prime} / \gamma^{\prime \prime}$ and $\delta$ precipitate in the microstructure. However, their distribution is not uniform owing to the local compositional segregation. As described previously, $\gamma^{\prime} / \gamma^{\prime \prime}$ and $\delta$ predominantly precipitate around the Laves phase in the interdendritic region. As the bottom of the sample spends more time at a higher temperature than the top, there will be a difference in the amount of $\gamma^{\prime} / \gamma^{\prime \prime}$ and $\delta$ between the bottom and top. Such a heterogenous distribution along the height as well as from the dendrite core to the interdendritic region has been reported by $\mathrm{Z}$. Li et al. [34].

It should be noted that for all these thermal cycles, the Laves phase formed during the non-equilibrium solidification of a given layer does not significantly change owing to the thermal cycling that occurs during subsequent layer depositions. This is primarily due to the fact that in these thermal cycles, the time-temperature conditions are not sufficient to dissolve the Laves phase significantly. Therefore, to modify the Laves phase, the process parameters of the L-DED should be changed so that the thermal conditions during non-equilibrium solidification change; otherwise, post-HT is necessary to alter the formed Laves phase. In should also be noted that the non-equilibrium solidification conditions (thermal gradients and cooling rates) can, to a certain degree, change during the deposition of the material owing to the geometry of the deposited part. This could influence the Laves phase formation locally during the non-equilibrium solidification from bottom to top of the build.

\subsection{Phase transformation during heat treatment of L-DEDed Alloy 718}

Heat treatments (homogenization, solution treatment, and ageing) are often used for Alloy 718 to remove compositional segregation and obtain the appropriate phase distribution so that desired mechanical properties for the required application may be obtained. Depending on 
Table 1

Standard heat treatment as per AMS5383 for cast Alloy 718

\begin{tabular}{|c|c|c|}
\hline Homogenization & Solution treatment & Ageing \\
\hline $\begin{array}{l}1093 \pm 14^{\circ} \mathrm{C} \text { for } 1 \sim 2 \mathrm{~h} \text {, followed by air } \\
\text { cooling or faster cooling }\end{array}$ & $\begin{array}{l}\text { (954 982) } \pm 14^{\circ} \mathrm{C} \text { for more than } 1 \mathrm{~h} \text {, followed } \\
\text { by air cooling or faster cooling }\end{array}$ & $\begin{array}{l}718 \pm 8^{\circ} \mathrm{C} \text { for } 8 \mathrm{~h} \text {, furnace cool to } 621 \pm 8^{\circ} \mathrm{C} \text { at } 55 \pm \\
8^{\circ} \mathrm{C} / \mathrm{h} \text {, hold at } 621 \pm 8^{\circ} \mathrm{C} \text { for } 8 \mathrm{~h} \text {, followed by air cooling }\end{array}$ \\
\hline
\end{tabular}

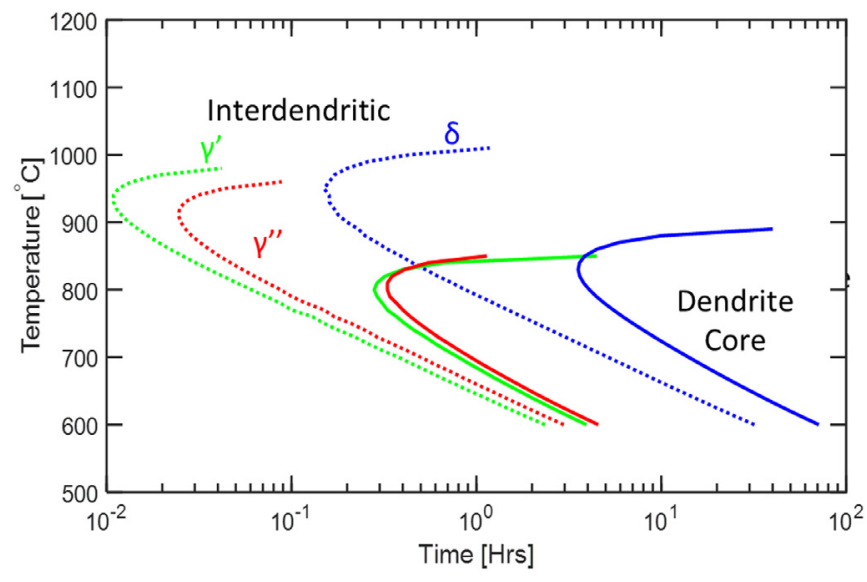

Fig. 9. TTT diagram obtained using the JMatPro software package by considering compositions in the dendrite core and the interdendritic region in Fig. 4(b). Dotted lines represent $0.5 \%$ precipitation close to Laves phase, and solid lines represent $0.5 \%$ precipitation in the dendrite core.

the initial microstructure and the final application, different HT combinations can be used.

In L-DED Alloy 718, the as-deposited (AD) microstructure varies according to the thermal conditions of the process, as described previously. Therefore, the HTs could be prepared according to the AD microstructure. In addition, the selection of HT is be influenced by the final application. For example, if L-DED was used to repair damaged or worn-out components, then the HT should be selected so that the base material of the component that is in fully heat-treated condition is not affected.

In the literature on post-HT for L-DED Alloy 718, the commonly used HTs are as per the AMS 5383 standard, which was originally developed for cast Alloy 718[4,27,41-47]. The details of this standard are shown in Table 1. Direct ageing (DA), solution treatment and ageing (STA), homogenization and STA (HSTA), and homogenization and ageing (HA) are the common HTs used for L-DED Alloy 718.

\subsubsection{Phase transformation during heat treatment of a microstructure resulting from thermal cycle $A$}

As mentioned in the previous section, thermal cycle A produces a microstructure with segregated $\gamma$ matrix, Laves, and MC phases. The presence of the compositional segregation in the matrix has a direct effect on the phase transformation during different post-HTs. To explain this transformation, time-temperature transformation (TTT) diagrams, as shown in Fig. 9, were generated using the JMatPro software package by considering the composition in the dendrite core and the interdendritic region from Fig. 4(b).

The JMatPro predictions indicate that there is a clear difference (more than an order of magnitude difference in time) in the precipitation kinetics of $\gamma^{\prime} / \gamma^{\prime \prime}$ and $\delta$ owing to the compositional segregation. In the interdendritic region, precipitates form more rapidly than in the dendrite core. Moreover, the nose of the TTT curves related to the interdendritic region (dotted lines) corresponds to a higher temperature than that of the curves related to the dendrite core (solid lines). Further, ageing treatment is performed to precipitate the strengthening phases $\gamma^{\prime} / \gamma^{\prime \prime}$. As shown in Fig. 5, the equilibrium volume fraction of $\gamma^{\prime} / \gamma^{\prime \prime}$ is higher in the interdendritic region than in the dendrite core. Accord- ingly, a high volume fraction of $\gamma^{\prime} / \gamma^{\prime \prime}$ forms toward the interdendritic region during DA treatment. The accelerated phase precipitation kinetics causes $\gamma^{\prime} / \gamma^{\prime \prime}$ to precipitate at an earlier stage of the HT in the interdendritic region than in the dendrite core. Hence, the $\gamma^{\prime} / \gamma^{\prime \prime}$ precipitates in the interdendritic region experience greater size growth than those in the dendrite core. From the segregation level of the elements forming $\gamma^{\prime}$ and $\gamma^{\prime \prime}$, as shown in Fig. 5, it is reasonable to assume that the growth of $\gamma^{\prime \prime}$ is supported more than that of $\gamma^{\prime}$. Therefore, even if the equilibrium predictions indicate a high volume fraction for $\gamma^{\prime}$ in the interdendritic region, this fraction may not be high compared with that of $\gamma^{\prime \prime}$.

The effect of element segregation on the precipitation of $\gamma^{\prime \prime}$ during DA MICRESS simulations performed using the AD microstructure related to thermal cycle A is shown in Fig. 10 (see Appendix B for modeling details). The results qualitatively agree with the experimental observations $[36,38]$. In contrast with the dendrite core, toward the interdendritic region, the number density and size of the precipitates increase. It can be assumed that owing to the lack of $\gamma^{\prime \prime}$ precipitates, the dendrite core is softer than the interdendritic area. Consequently, there is a mechanical property gradient from the dendrite core to the interdendritic region. However, at the macro level, this DA Alloy 718 microstructure possesses a relatively higher strength than in the as-built condition, as shown in Fig. 11. It should be noted that the temperature in DA treatment is not sufficiently high to dissolve/change a Laves phase or grain structure. Thus, the increase in strength in this condition compared with the $\mathrm{AD}$ condition is due to the precipitation of $\gamma^{\prime} / \gamma^{\prime \prime}$. This raises the fundamental question of explaining how DA L-DED Alloy 718 can result in relatively higher strength (in comparison with AMS5662 wrought standard) even though the distribution of strengthening phases is non-uniform in the microstructure. A possible reason could be that the microstructure has a property gradient from the dendrite core to the interdendritic region. This microstructure could be treated as a composite material having a softer phase (dendrite core area) embedded in a hard phase (interdendritic area). These two (soft and hard) areas mimic the dendritic structure inside the grain. Therefore, our hypothesis is that a hierarchical structure with these two phases and its spatial structure inside the grains give rise to the higher strength on the macro scale. This could be verified by using crystal plasticity/finite element modeling to study the effect of such a composite microstructure on macroscale properties; this is left for future work.

Solution treatment and ageing is another type of HT that is used in L-DED Alloy 718. Here, the AD microstructure is first subjected to solution treatment followed by ageing. The solution treatment according to AMS5383 is used to precipitate the $\delta$ phase at the grain boundaries, as it is performed below the $\delta$ solvus temperature. The presence of the $\delta$ phase at the grain boundaries has been demonstrated to have a beneficial effect on stress rupture ductility, and to inhibit the growth tendency of the matrix grains during the forging process [48-50]. However, the presence of a compositional segregation in AD L-DED microstructure causes $\delta$ to precipitate inside the grains as well, owing to the presence of multiple dendrite/cells inside a single grain. In the interdendritic area, the $\delta$ phase precipitates and grows in large quantities owing to the large equilibrium volume fraction (Fig. 5) and increased precipitation kinetics (Fig. 9). In addition, the Laves phase in the AD structure is also dissolved to some extent. However, the amount of dissolution depends on the solution treatment temperature. At low temperatures, the dissolution of the Laves phase is slower. This is evident from the simulations performed by C. Kumara et al. [23] and the experimental observations [38,42,51] (Fig. 12). Similar observations have been made for laser- 


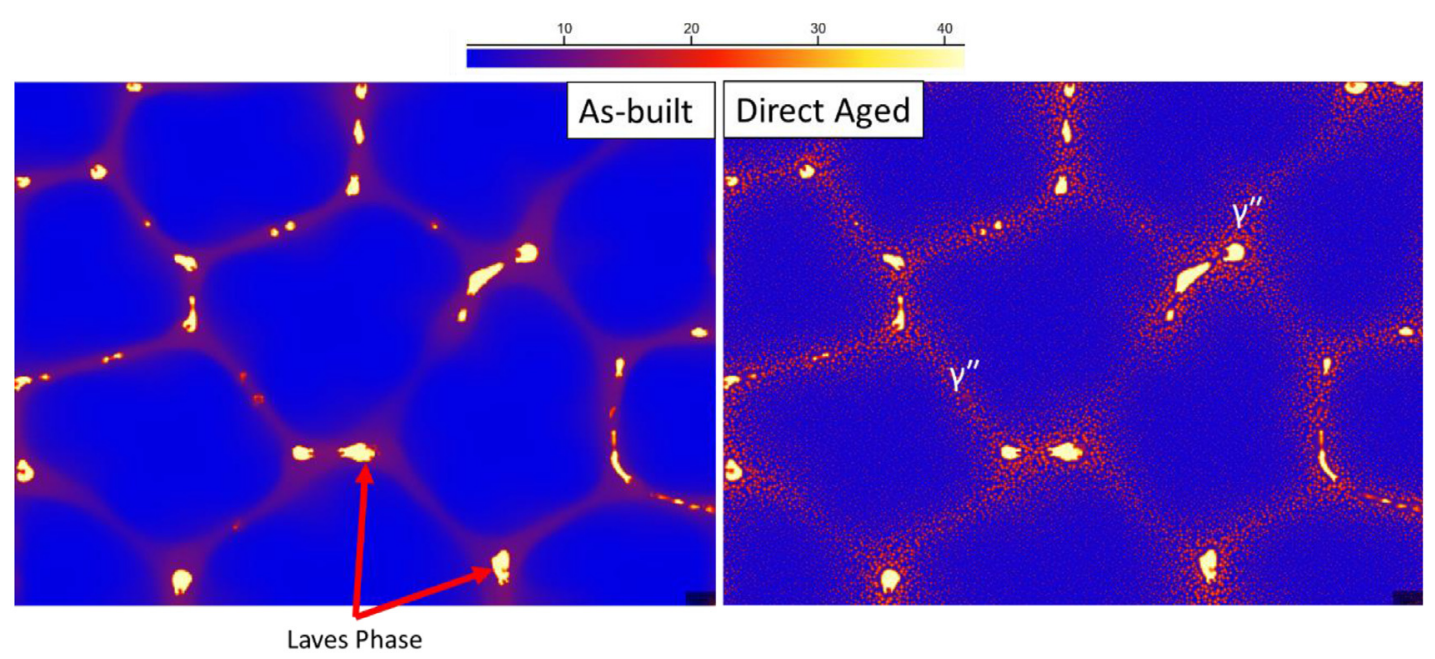

Fig. 10. MICRESS simulated AD microstructure at the end of thermal cycles similar to thermal cycle-A, and the same microstructure after DA simulation. Domain size $25 \mu \mathrm{m} \times 20 \mu \mathrm{m}$. Scale shows the $\mathrm{Nb}$ distribution in $\mathrm{wt} \%$. Note: See Appendix B for details about the modelling work.

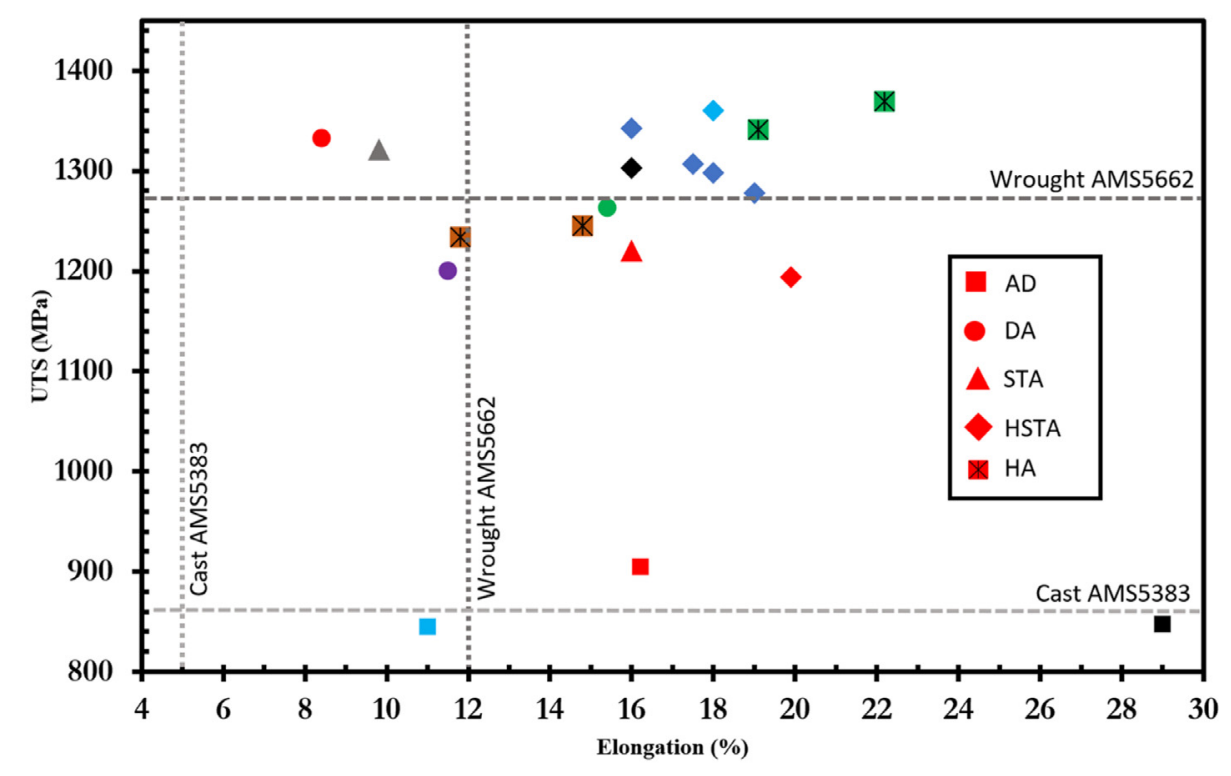

$\mathrm{AD}$

$\downarrow \operatorname{Hom}\left(1080{ }^{\circ} \mathrm{C} / 1.5 \mathrm{~h} / \mathrm{AC}\right)+\operatorname{STA}\left(980^{\circ} \mathrm{C} / 1 \mathrm{~h} / \mathrm{AC}+720^{\circ} \mathrm{C} / 8 \mathrm{~h} / \mathrm{FC} / 620^{\circ} \mathrm{C} / 8 \mathrm{~h} / \mathrm{AC}\right)$

- Hom $\left(1080{ }^{\circ} \mathrm{C} / 1.5 \mathrm{~h} / \mathrm{AC}\right)+\operatorname{STA}\left(980^{\circ} \mathrm{C} / 1 \mathrm{~h} / \mathrm{AC}+720^{\circ} \mathrm{C} / 8 \mathrm{~h} / \mathrm{FC} / 620^{\circ} \mathrm{C} / 8 \mathrm{~h} / \mathrm{AC}\right)$

- $\mathrm{DA}\left(718^{\circ} \mathrm{C} / 8 \mathrm{~h} / \mathrm{FC} / 621^{\circ} \mathrm{C} / 8 \mathrm{~h} / \mathrm{AC}\right)$

$\triangle \operatorname{STA}\left(980^{\circ} \mathrm{C} / 1 \mathrm{~h} / \mathrm{AC}+718^{\circ} \mathrm{C} / 8 \mathrm{~h} / \mathrm{FC} / 621^{\circ} \mathrm{C} / 8 \mathrm{~h} / \mathrm{AC}\right)$

- Hom $\left(1093{ }^{\circ} \mathrm{C} / 1-2 \mathrm{~h} / \mathrm{AC}\right)+\operatorname{STA}\left(980^{\circ} \mathrm{C} / 1 \mathrm{~h} / \mathrm{AC}+718^{\circ} \mathrm{C} / 8 \mathrm{~h} / \mathrm{FC} / 621{ }^{\circ} \mathrm{C} / 8 \mathrm{~h} / \mathrm{AC}\right)$

- $\operatorname{DA}\left(720^{\circ} \mathrm{C} / 8 \mathrm{~h} / \mathrm{FC} / 620^{\circ} \mathrm{C} / 8 \mathrm{~h} / \mathrm{AC}\right)$

\$ $\operatorname{Hom}\left(1100^{\circ} \mathrm{C} / 0.5 \mathrm{~h} / \mathrm{WQ}\right)+\mathrm{DA}\left(720^{\circ} \mathrm{C} / 8 \mathrm{~h} / \mathrm{FC} / 620^{\circ} \mathrm{C} / 8 \mathrm{~h} / \mathrm{AC}\right)$

区 Hom $\left(1100^{\circ} \mathrm{C} / 1 \mathrm{~h} / \mathrm{WQ}\right)+\mathrm{DA}\left(720^{\circ} \mathrm{C} / 8 \mathrm{~h} / \mathrm{FC} / 620^{\circ} \mathrm{C} / 8 \mathrm{~h} / \mathrm{AC}\right)$

$\mathrm{AD}$

- Hom $\left(1093 \pm 14{ }^{\circ} \mathrm{C} / 2 \mathrm{~h} / \mathrm{AC}\right)+\operatorname{STA}\left(954-980^{\circ} \mathrm{C} />1 \mathrm{~h} / \mathrm{AC}+718 \pm 8{ }^{\circ} \mathrm{C} / 8 \mathrm{~h} / \mathrm{FC} / 621 \pm 8{ }^{\circ} \mathrm{C} / 8 \mathrm{~h} / \mathrm{AC}\right)$

- $\operatorname{DA}\left(720^{\circ} \mathrm{C} / 8 \mathrm{~h} / \mathrm{FC} / 620^{\circ} \mathrm{C} / 8 \mathrm{~h} / \mathrm{AC}\right)$

* Hom $\left(1050^{\circ} \mathrm{C} / 15 \mathrm{~min} / \mathrm{WQ}\right)+\mathrm{DA}\left(720^{\circ} \mathrm{C} / 8 \mathrm{~h} / \mathrm{FC} / 620^{\circ} \mathrm{C} / 8 \mathrm{~h} / \mathrm{AC}\right.$

* $\operatorname{Hom}\left(1050^{\circ} \mathrm{C} / 45 \mathrm{~min} / \mathrm{WQ}\right)+\mathrm{DA}\left(720^{\circ} \mathrm{C} / 8 \mathrm{~h} / \mathrm{FC} / 620^{\circ} \mathrm{C} / 8 \mathrm{~h} / \mathrm{AC}\right)$

$\triangle \operatorname{STA}\left(954^{\circ} \mathrm{C} / 1 \mathrm{~h} / \mathrm{AC}+732 \mathrm{C} / 8 \mathrm{~h} / \mathrm{FC} / 599 \mathrm{C} / 8 \mathrm{~h} / \mathrm{AC}\right)$

$\diamond \operatorname{Hom}\left(1100{ }^{\circ} \mathrm{C} / 1.5 \mathrm{~h} / \mathrm{AC}\right)+\operatorname{STA}\left(980^{\circ} \mathrm{C} / 1 \mathrm{~h} / \mathrm{AC}+720^{\circ} \mathrm{C} / 8 \mathrm{~h} / \mathrm{FC} / 620^{\circ} \mathrm{C} / 8 \mathrm{~h} / \mathrm{AC}\right)$
Fig. 11. Ultimate tensile strength vs elongation of L-DED Alloy 718. Data taken from [4,27,41-47]. 


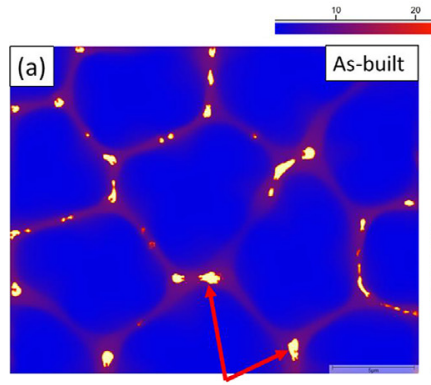

Laves Phase

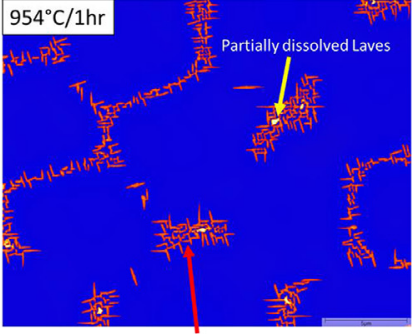

$\delta$ Phase
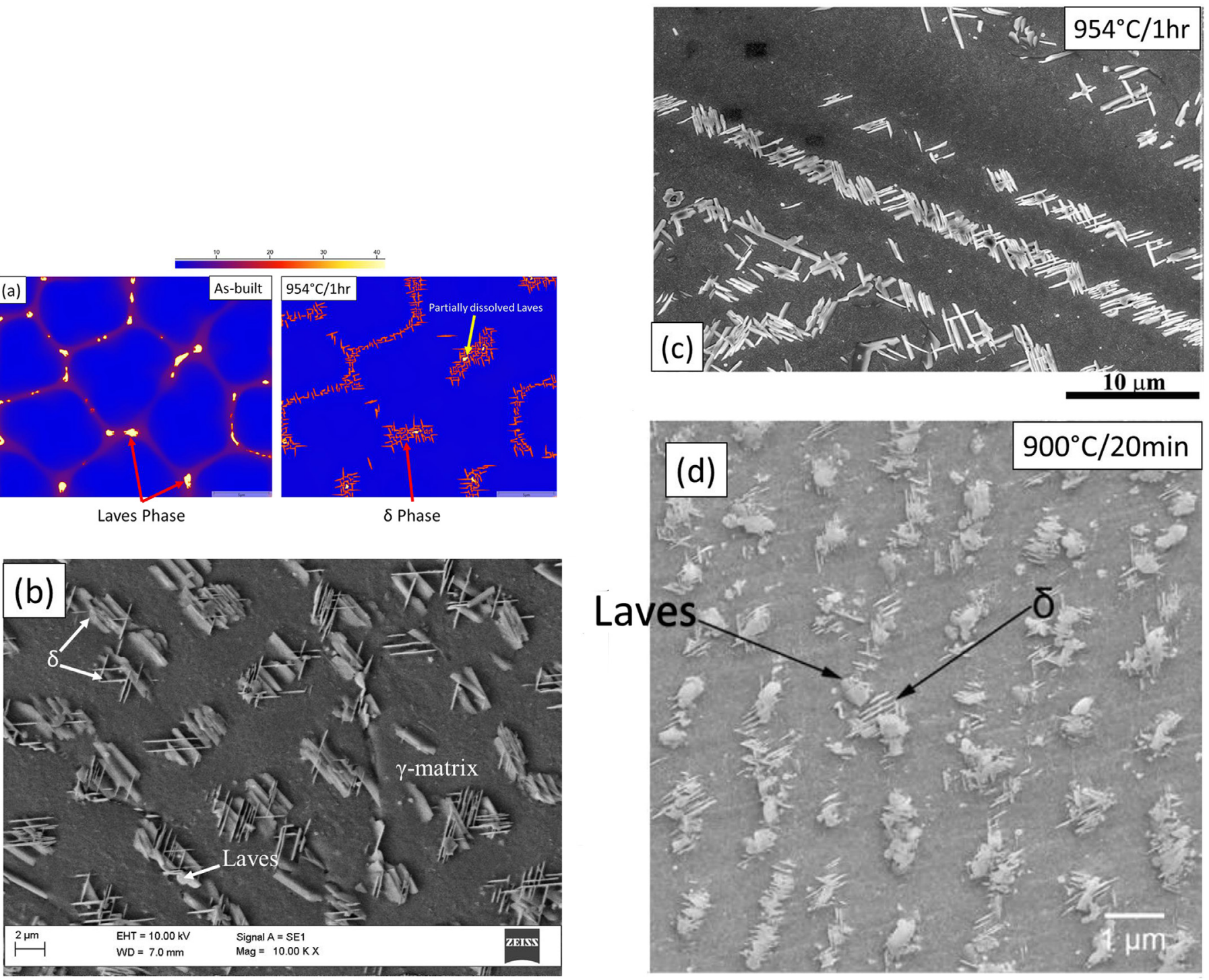

Fig. 12. Precipitation of $\delta$ phase in the interdendritic region in L-DED microstructures subjected to solution treatment.

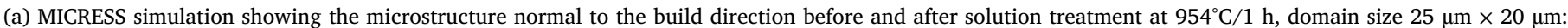
Fig. shows the $\mathrm{Nb}$ distribution in $\mathrm{wt} \%$.

Note: MICRESS simulation results were taken from a previous simulation work published in [23].

(b) Microstructure normal to the build direction after $954^{\circ} \mathrm{C} / 1 \mathrm{~h}$ [23].

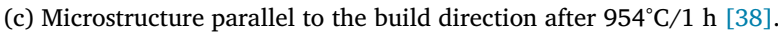

(d) Microstructure parallel to the build direction after $900^{\circ} \mathrm{C} / 20 \mathrm{~min}$ [51].

welded Alloy 718 subjected to solution treatment [27]. The amount of $\delta$ that precipitates in the interdendritic region is also affected by the solution treatment temperature. The volume fraction of $\delta$ is higher for a solution treatment at $954^{\circ} \mathrm{C}$ than at $980^{\circ} \mathrm{C}$ (see Fig. 5). No evidence of precipitation of $\gamma^{\prime} / \gamma^{\prime \prime}$ has been reported in the literature at the solution treatment temperatures even though the JMatPro predictions indicate that there could be a possibility of $\gamma^{\prime} / \gamma^{\prime \prime}$ precipitation (see Fig. 9). As $\delta$ is rich in $\mathrm{Nb}$, its precipitation consumes a certain level of $\mathrm{Nb}$ from the matrix phase. Therefore, during ageing HT (after the solution treatment), a lower volume fraction of $\gamma^{\prime \prime}$ could be expected than during DA. As the $\delta$ phase is incoherent with the $\gamma$ matrix, it does not contribute to the strength of the Alloy 718 as much as the coherent and semicoherent $\gamma^{\prime}$ and $\gamma^{\prime \prime}$ phases, respectively.

Homogenization HT is performed to dissolve the non-equilibrium Laves phase and homogenize the compositional segregation resulting from the non-equilibrium solidification. L-DED Alloy 718 produces a microstructure with a finer length scale than that in cast Alloy
718. Therefore, the Laves phase in L-DED Alloy 718 has a smaller size. In addition, L-DED produces a smaller dendritic structure than in the cast material. Thus, its compositional segregation length scale is smaller. Consequently, the homogenization kinetics of L-DED Alloy 718 is faster than that of cast Alloy 718; this is evident in the study by Shang Sui et al. [52]. As the homogenization temperature increases, the dissolution of the Laves phase is faster, and eventually homogenization of the composition will occur. However, whether this treatment results in a fully homogenized matrix without any Laves phases depends on the Laves particle size, dendrite arm spacing, HT temperature, and time. During the treatment, $\gamma^{\prime} / \gamma^{\prime \prime}$ and $\delta$ do not form in the material, as the temperature is above their precipitation temperature window. In addition, MC present in the microstructure is not affected significantly, and grain growth is commonly observed $[4,25,43,45]$. Similar observations can be made regarding the homogenization of microstructures formed by thermal cycles $\mathrm{B}$ and $\mathrm{C}$. 
If STA or DA were to be performed after homogenization HT, the phase transformation kinetics would be different, as the chemical composition in the $\gamma$ matrix is different from that in the AD condition. Owing to the relatively homogenized composition in the $\gamma$ matrix after homogenization HT, the $\delta$ phase tends to precipitate mainly at grain boundaries during the $1 \mathrm{~h}$ solution treatment of STA $[25,43,53]$. At a grain boundary, the nucleation energy barrier for solid-state precipitation of a phase is less than that of the defect-free matrix [54]. In addition, $\delta$ could also precipitate at twin boundaries within the grains because a twin boundary also has a lower energy barrier for nucleation [55]. The amount of $\delta$ that precipitates during the $1 \mathrm{~h}$ solution treatment is below the equilibrium volume fraction of $\delta$ at that temperature; this is evident from the study by S. Azadian et al. [11]. Therefore, the precipitated $\delta$ during the solution treatment does not consume the $\mathrm{Nb}$ entirely, and there remains a sufficient amount of Nb to precipitate $\gamma^{\prime \prime}$ during ageing HT. However, the $\mathrm{Nb}$ depletion at the vicinity of the $\delta$ precipitate hinders the $\gamma^{\prime \prime}$ precipitation, resulting in a $\gamma^{\prime \prime}$-free zone around the $\delta$ phase [10].

During ageing HT, the strengthening phases mainly start to precipitate uniformly owing to the homogenized elemental distribution [4]. However, during the precipitation and growth of $\gamma^{\prime}$ and $\gamma^{\prime \prime}$, the local chemical composition near the vicinity of the precipitate could change due to difference in solubility of elements in these phases. This could affect the nucleation and growth of secondary precipitates of $\gamma^{\prime}$ and $\gamma^{\prime \prime}$ [56]. As seen in Fig. 11, these $\gamma^{\prime} / \gamma^{\prime \prime}$ that precipitate and grow during aging HT will increase the strength of the material

\subsubsection{Phase transformation during heat treatment of a microstructure resulting from thermal cycle $B$}

As mentioned above, thermal cycle $\mathrm{B}$ results in a microstructure that contains Laves, MC, and $\gamma^{\prime} / \gamma^{\prime \prime}$ phases. Therefore, the phase transformation during the HT is rather complex. Performing STA may not be suitable for this microstructure, as the existing $\gamma^{\prime \prime}$ can act as nucleation sites (stacking faults in the $\gamma^{\prime \prime}$ particles) that precipitate and grow $\delta$ phases at the solution treatment temperatures $[10,11]$. Laves-phase dissolution can be expected to a certain degree, as mentioned in Section 3.2.1.

During DA, $\gamma^{\prime} / \gamma^{\prime \prime}$ phases in the AD condition can be expected to grow, as the temperature conditions favor their growth. In addition, the precipitation gradient observed in the build direction of the microstructure is reduced. No changes to the Laves phase can be expected, as the temperature is so low that cannot dissolve them.

\subsubsection{Phase transformation during heat treatment of a microstructure resulting from thermal cycle $C$}

Thermal cycle $\mathrm{C}$ results in a microstructure that contains Laves, $\delta$, MC, and $\gamma^{\prime} / \gamma^{\prime \prime}$. Performing STA may not be suitable for this microstructure, as the existing $\gamma^{\prime \prime}$ can act as nucleation site for the precipitation and growth of $\delta$. In addition, the existing $\delta$ can also grow larger in size. The Laves phase will dissolve only to a certain degree in this case as well.

During DA, $\gamma^{\prime} / \gamma^{\prime \prime}$ phases in the AD condition can be expected to grow, as the temperature conditions favor their growth. The existing $\delta$ phase is expected to be unaffected during ageing HT [55]. No changes to the Laves phase can be expected.

It should be noted that no data are available in literature relating to Sections 3.2.2 and 3.2.3. Thus, the discussion provided is based on the understanding of phase transformations presented in previous sections and references therein.

\section{Electron-beam powder-bed fusion}

Electron-beam melting is a type of powder-bed AM technique that was first commercialized in 1997 by Arcam Corporation in Sweden. In the EB-PBF process, an electron beam is used to selectively melt the material in a layer-by-layer manner. This process has unique advantages in relation to the manufacturing of biomedical implants and highperformance components used in aerospace and high-temperature appli- cations: higher build rates owing to high beam energy and speed, lower residual stresses (due to elevated powder bed temperature), the possibility of tailoring the microstructure $[34,57,58]$, and reduced oxidation issues [59]. However, owing to the inherent nature of this process, the semi-sintered powder is difficult to remove from complex geometries. Components manufactured by EB-PBF have higher surface roughness than those manufactured by LB-PBF and may thus require posttreatment.

\subsection{Phase transformation during the EB-PBF processing of Alloy 718}

Owing to the inherent nature of this process, the printed material undergoes multiple thermal cycles when successive layers are printed. During this sequential printing, the uppermost layers undergo remelting. Depending on the beam parameters and movement, the number of layers that are remolten varies. When layer melting/remelting occurs, nonequilibrium solidification takes place, as discussed in Section 2. The resulting as-solidified microstructure has a segregated dendritic structure with interdendritic Laves and NbC phases [14,60]. Upon building further layers, the microstructure experiences thermal cycling. However, it does not change significantly by the thermal cycles owing to their shorter exposure time. The most significant effect on the microstructure is exerted by the elevated build temperature that occurs during the EB$\mathrm{PBF}$ processing of Alloy 718. This temperature acts as an in situ HT and causes microstructural changes. As each layer that is built is exposed to the elevated temperature for a different amount of time, there exists a microstructure gradient from the top to the bottom layer. Once the printing is completed, the obtained part is cooled down by injecting helium into the build chamber. During this cooling, further phase transformations take place.

D. Deng et al. [14] and Kumara et al. [24] investigated the effect of the elevated build temperature on the as-solidified microstructure through experiments and modeling. The thermocouple data from the bottom of the build plate from these studies are shown in Fig. 13. It is evident that throughout the building process, the global temperature of the powder bed was greater than $1020^{\circ} \mathrm{C}$. It was demonstrated that this temperature caused the material to homogenize, gradually toward the bottom, by dissolving the Laves phase and homogenizing the element distribution in the matrix. Furthermore, this diffuse region extended between $150 \mu \mathrm{m}$ to $1800 \mu \mathrm{m}$ from the top layer. Beyond $1800 \mu \mathrm{m}$, a fully homogenized region was observed. This homogenization process was accelerated by the smaller dendrite spacing and hence smaller segregation length scale and smaller Laves-phase particle size. The MC phase was not affected by this in situ treatment, as it was more stable. No precipitation of $\delta$ and $\gamma^{\prime} / \gamma^{\prime \prime}$ was expected during printing, as the temperature was above the precipitation windows of these phases. Precipitation of $\delta$ and $\gamma^{\prime} / \gamma^{\prime \prime}$ took place during the cooling stage of the process, as the temperature dropped through the precipitation windows of these phases. In the as-solidified region, $\delta$ and $\gamma^{\prime} / \gamma^{\prime \prime}$ precipitated primarily in the interdendritic region owing to the high $\mathrm{Nb}$ segregation. In the transition region (150-1800 $\mu \mathrm{m})$ the precipitation level was influenced by the change in the local chemical composition. In the homogenized region, few $\delta$ particles were observed at high-angle grain boundaries. This can be attributed to the cooling stage, as the microstructure spent $\sim 15 \mathrm{~min}$ in the $\delta$ precipitation window. The $\gamma^{\prime} / \gamma^{\prime \prime}$ phase also precipitated uniformly owing to the relatively homogenized composition in this region, resulting in a hardness of $\sim 420 \mathrm{HV}$. This value indicates that a significant volume fraction of $\gamma^{\prime} / \gamma^{\prime \prime}$ precipitated during the cooling. The time that the microstructure spent in the $\gamma^{\prime} / \gamma^{\prime \prime}$ precipitation window was $\sim 60 \mathrm{~min}$. This indicates that the average cooling rate that the material experienced in the $\gamma^{\prime} / \gamma^{\prime \prime}$ process window was approximately $5^{\circ} \mathrm{C} / \mathrm{min}$. Similar hardness observations have been reported in the as-built condition of EB-PBF Alloy $718[61,62]$. These observations agree well with continuous cooling experiments conducted by L. Geng et al. for wrought Alloy 718[63]. In the following section, it has been demonstrated that this cooling down 


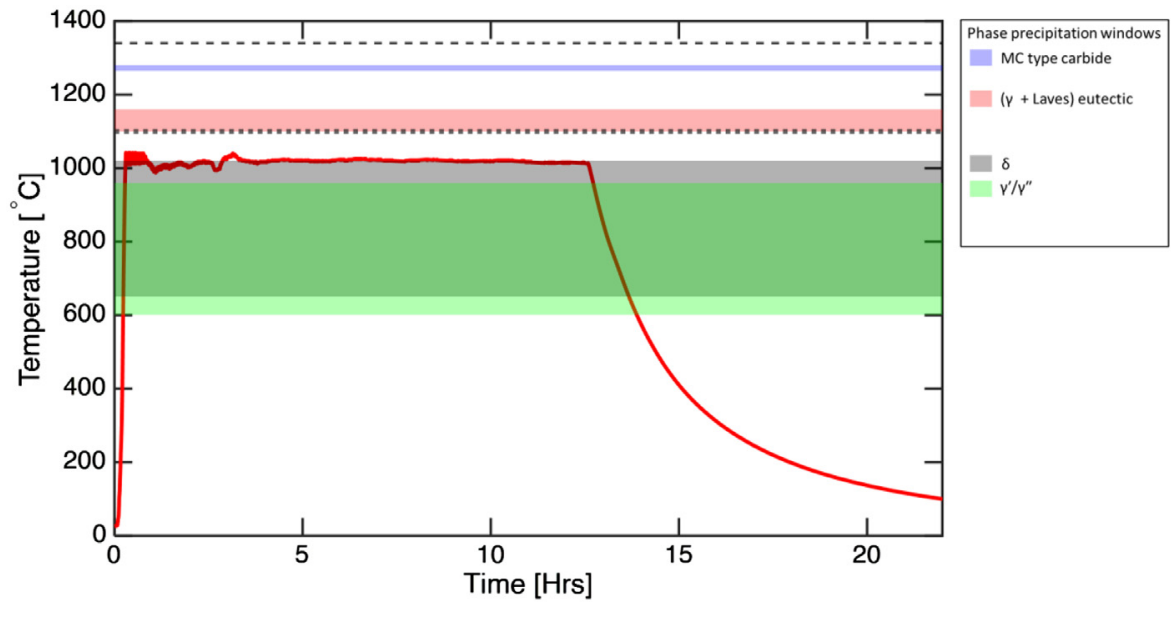

Fig. 13. Thermocouple measurement from the bottom of the build plate of the EB-PBF process. Raw data taken from D. Deng et al. [14] and Kumara et al. [24].

Table 2

Standard heat treatment as per ASTM F3055 for cast Alloy 718

\begin{tabular}{|c|c|c|}
\hline HIP & Solution treatment & Ageing \\
\hline \multirow[t]{2}{*}{$\begin{array}{l}1120 \text { to } 1185 \pm 15^{\circ} \mathrm{C} \text { in an inert atmosphere } \\
\text { for } 240 \pm 60 \mathrm{~min} \text { at } \geq 100 \mathrm{MPa} \text {, followed by } \\
\text { furnace cooling to }<425^{\circ} \mathrm{C}\end{array}$} & $\begin{array}{l}1066 \pm 14^{\circ} \mathrm{C} \text { (except not below } 1038^{\circ} \mathrm{C} \text { ) for } 1 \sim 2 \mathrm{~h} \text {, } \\
\text { followed by air cooling or faster cooling }\end{array}$ & $\begin{array}{l}760 \pm 8^{\circ} \mathrm{C} \text { for } 10 \pm 0.5 \mathrm{~h} \text {, furnace cool to } 649 \pm \\
8^{\circ} \mathrm{C} \text {, hold at } 649 \pm 8^{\circ} \mathrm{C} \text { for total precipitation time } \\
\text { of } 20 \mathrm{~h} \text {, followed by air cooling or faster cooling }\end{array}$ \\
\hline & $\begin{array}{l}927 \sim 1010 \pm 14^{\circ} \mathrm{C} \text { for } 1 \mathrm{~h} \text { (except not exceeding } \\
1016^{\circ} \mathrm{C} \text { ), followed by air cooling or faster cooling }\end{array}$ & $\begin{array}{l}718 \sim 760 \pm 8^{\circ} \mathrm{C} \text { for } 8 \mathrm{~h} \text {, furnace cool to } 621 \pm 8^{\circ} \mathrm{C} \text {, } \\
\text { hold at } 621 \pm 8^{\circ} \mathrm{C} \text { for total precipitation time of } \\
18 \mathrm{~h} \text {, followed by air cooling or faster cooling }\end{array}$ \\
\hline
\end{tabular}

stage can be used as an alternative method for ageing HT in some applications.

Kirka et al. [60] have also investigated the microstructure development in EB-PBF Alloy 718. However, unlike in D. Deng et al. [12] and Kumara et al. [21], the powder-bed elevated temperature was maintained at $\sim 975^{\circ} \mathrm{C}$. As this is within the $\delta$ precipitation window, the $\delta$ phase precipitated at grain boundaries as well as within the matrix during the building process. The transition region, in this case, was longer, as the bed temperature was lower. The amount of $\delta$ phase increased toward the bottom of the sample, as the bottom layers of the sample remained for a longer time at $\sim 975^{\circ} \mathrm{C}$ than the top layers. Therefore, the volume fraction $\gamma^{\prime \prime}$ that precipitated during the cooling stage of the process was higher toward the top of the sample than the bottom. The consequence of such heterogeneity with height is evident in the reported room-temperature mechanical properties. As the distance from the bottom of the build increased, the yield and tensile strength as well as elongation gradually increased [60].

\subsection{Phase transformation during heat treatment of EB-PBF Alloy 718}

For EB-PBF Alloy 718, post-HTs are typically used to remove the heterogeneous phase distribution and reduce defects (porosity and lack of fusion) so that the required mechanical performance may be achieved [64]. The HIP and post-HT protocols for EB-PBF Alloy 718, as recommended in the ASTM F3055 standard [65], are shown in Table 2.

HIP is mainly carried out to heal defects (porosity and lack of fusion) in the as built material. However, Oxides present at the defect surface prevent complete healing of defects after HIP [66]. As this is performed at high temperature $\left(>1100{ }^{\circ} \mathrm{C}\right)$ for a longer period $(\sim 4 \mathrm{~h})$, different phases (Laves, $\delta$, and $\left.\gamma^{\prime} / \gamma^{\prime \prime}\right)$ in the as-built condition completely dissolve back into the matrix phase $[67,68]$. However, owing to the hightemperature stability, carbides do not dissolve during this process [67]. At the end of the HIP cycle, the chemical composition of the matrix can be considered homogenized. However, to prevent phase transformation during the cooling-down part of the HIP cycle, a rapid cooling (quenching) must be performed, at the end of which, the microstructure is re- ported to have a $\gamma$ matrix that has homogenized chemical composition and is precipitation free, except for carbides [69].

After the HIP cycle, the EB-PBF Alloy 718 is subjected to STA or $\mathrm{DA}$, depending on the requirements and application. If rapid quenching can be performed, then the solution treatment at $1066^{\circ} \mathrm{C}$ is redundant, as this does not cause any phase precipitation; otherwise, solution treatment at $1066^{\circ} \mathrm{C}$ is necessary to dissolve the undesired phase distribution. However, compared with HIP, solution treatment involves relatively low temperature and holding time, and therefore complete phase dissolution may or may not be achieved. Balachandramurthi et al. [61] reported that after $1066{ }^{\circ} \mathrm{C} / 1 \mathrm{~h}$, a certain $\delta$-phase level was observed at some grain boundaries. However, their size was reduced compared with that in the as-built condition owing to the dissolution process during the solution treatment. D. Deng et al. [70] reported complete dissolution of the $\delta$ phase after treating EBM Alloy 718 at $1080^{\circ} \mathrm{C} / 1 \mathrm{~h}$. It is worth mentioning that the size of the $\delta$ phase in the as-built condition observed by $\mathrm{D}$. Deng et al. [70] was smaller than that observed by Balachandramurthi et al. [61].

After the HIP cycle with rapid quenching, to control the precipitation of the $\delta$ phase in the material, solution HT should be performed within the $\delta$ precipitation window. In such solution treatments, grain-boundary $\delta$ precipitation is primarily observed [70]. As discussed in Section 3.2.1, solution treatment at the lower end of the $\delta$ window will result in a higher volume fraction owing to the higher equilibrium volume fraction. In EB-PBF Alloy 718, S. Goel [71] observed greater precipitation of the $\delta$ phase after solution treatment at $954{ }^{\circ} \mathrm{C}$ than at $980^{\circ} \mathrm{C}$, both performed for $1 \mathrm{~h}$. Furthermore, as discussed in Section 3.2.1, the amount of $\delta$ that precipitates during the $1 \mathrm{~h}$ solution treatment does not give rise to the equilibrium volume fraction of $\delta$ at the solution HT temperature.

S. Goel [71] demonstrated the possibility of performing STA inside the HIP vessel combined with the HIP cycle, thereby retaining a high pressure during STA. In this combined cycle, the argon gas pressure inside the HIP vessel was retained above $100 \mathrm{MPa}$. However, the solution treatment performed at $980{ }^{\circ} \mathrm{C}$ with pressure $(\sim 160 \mathrm{MPa})$ did not yield any $\delta$ precipitation in the microstructure, compared with the same solution treatment performed without pressure. This could be explained by the Clausius-Clapeyron relation [54] (Equation (1)), which describes 
Table 3

Theoretical calculations of Clausius-Clapeyron relation values using values from TTNI8 database

\begin{tabular}{lllll}
\hline Phase & $\Delta H_{\gamma \rightarrow \text { precipitate }}(\mathrm{kJ} / \mathrm{mol})$ & $T_{\text {eq }}(\mathrm{K})$ & $\Delta V^{*}=V_{\gamma}-V_{\text {precipitate }}\left(10^{-6} \mathrm{~m}^{3} / \mathrm{mol}\right)$ & $\frac{d T_{\text {eq }}}{d P}(\mathrm{~K} / 100 \mathrm{MPa})$ \\
\hline$\delta$ & 27.8 & 1283 & $7.3-7.9=-0.6$ & -2.8 \\
$\gamma^{\prime \prime}$ & 27.2 & 1203 & $7.3-7.8=-0.5$ & -2.8 \\
$\gamma^{\prime}$ & 34.9 & 1140 & $7.3-7.6=-0.3$ & -0.98 \\
\hline
\end{tabular}

* calculated using the data from TCNI8 database since volume data is not available in TTNI8

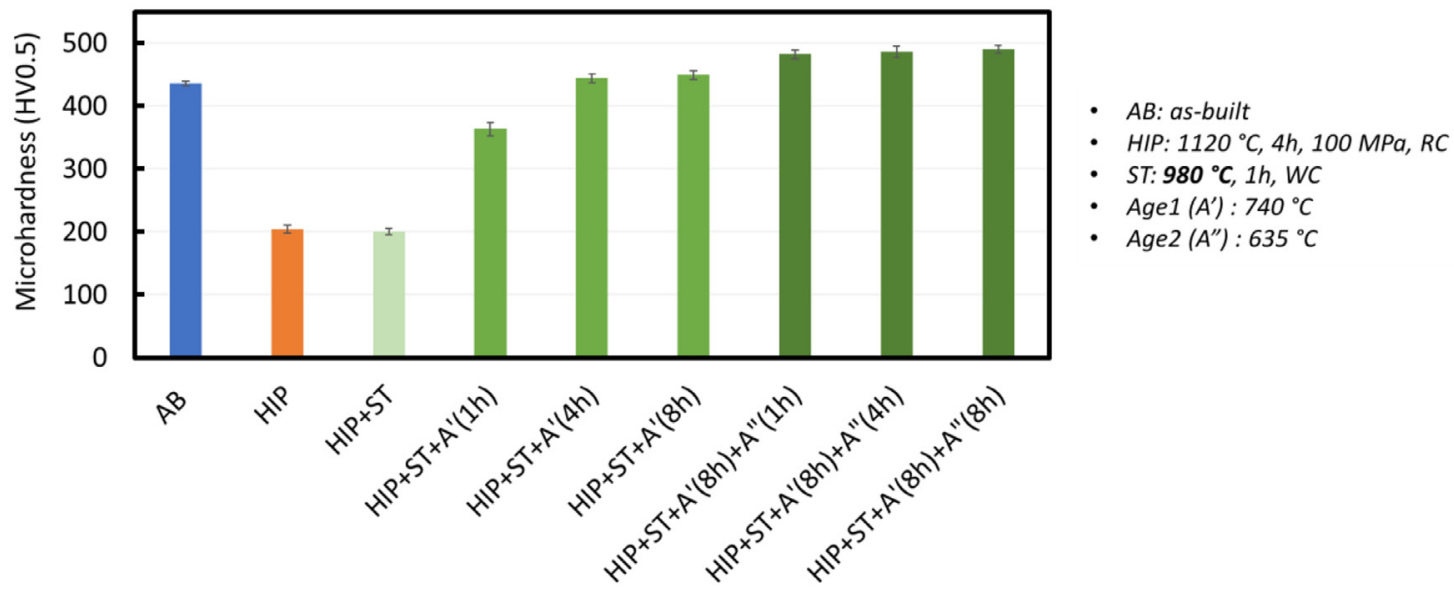

Fig. 14. Microhardness of the as-built and post-treated specimens of EB-PBF Alloy 718[71].

the effect of pressure on the phase-transformation equilibrium temperature in a given system.

$\frac{d T_{e q}}{d P}=\frac{T_{e q} \Delta V}{\Delta H}$

Here, $P$ is the pressure, $T_{e q}$ is the equilibrium phase-transformation temperature, $\Delta H$ is the enthalpy change, and $\Delta V$ is the molar volume difference between the two phases during phase transformation. If $\frac{d T_{e q}}{d P}<0$, then an increase in pressure will suppress the phase equilibrium temperature, which is the case for the $\delta$ phase, as seen from the theoretical calculation of the Clausius-Clapeyron relation (Table 3). One can argue that the values shown in Table 3 may have a negligible effect in reality. However, the purpose of this theoretical calculation is to demonstrate that an increase in pressure will lower the equilibrium temperature of the $\gamma^{\prime} / \gamma^{\prime \prime}$ and $\delta$ phases. Experiments are required to confirm the exact level of drop in the equilibrium temperature owing to the elevated pressure on Alloy 718.

Finally, ageing HT is performed to increase the material strength by precipitating the strengthening phases. Owing to the homogenized composition distribution state of the $\gamma$ matrix after the previous HTs, strengthening precipitation occurs uniformly in the matrix, thereby resulting in increased hardness of the material [71]. S. Goel et al. [67] demonstrated that regardless of the initial variation in the hardness of EB-PBF Alloy 718, after HIP and HT involving ageing, higher and uniform hardness can be obtained. It is worth mentioning that HT operations used for conventional cast and wrought Alloy 718 are typically employed for EB-PBF Alloy 718 [58,72,73]. This is also reflected in the ASTM F3055 standard for PBF Alloy 718, where the HT parameters appear to be taken from the existing AMS 5363 standard for cast [74], and the AMS 2774 standard for wrought Alloy 718[75]. However, as stated previously, it is evident from the literature that the microstructure of conventional cast-wrought Alloy 718 is highly different from that of EB-PBF or other AM Alloy 718[20,76,77]. Thus, using standard cast-wrought Alloy 718 HT procedures may not be the ideal solution for EB-PBF materials. Therefore, there is a need for exploring HT protocols tailored to such materials. Previous work by the authors' research group has demonstrated that, for precipitation of strengthening phases in EBPBF Alloy 718, the HT time (particularly for ageing) can be significantly reduced compared with the schedule recommended in the ASTM F3055 standard (see Fig. 14) [71,78].

In Fig. 14, it is seen that the hardness of the Alloy 718material was significantly reduced after the HIP treatment $\left(1120^{\circ} \mathrm{C}, 4 \mathrm{~h}, 100 \mathrm{MPa}\right)$. This is expected, as HIP dissolves the strengthening phases completely, and the application of fast cooling after the holding time inhibits any significant re-precipitation [63]. In addition, as explained earlier, HIP treatment results in a matrix that has a homogenized composition distribution, with compositional values close to those of the nominal composition of the Alloy 718. It was observed that in the first ageing step (Age 1), hardness increased as the ageing time increased from $1 \mathrm{~h}$ to 4 $\mathrm{h}$, and with prolonged holding at the Age 1 temperature for $4 \mathrm{~h}$, no further hardness change was noticed. Similarly, during the second ageing step (Age 2, following an $8 \mathrm{~h}$ treatment in the first step), hardness increased after $1 \mathrm{~h}$ of holding time. However, no further effect on hardness was observed for longer holding time. Therefore, hardness appeared to flatten after $4 \mathrm{~h}$ for Age 1, and after $1 \mathrm{~h}$ for Age 2. These results are indicative of the possibility to reduce the duration of traditional double ageing treatment. Detailed microstructure characterization related to evaluating the shortening of the ageing time and the correlation with hardness is part of another ongoing study in the authors' research group. A similar hardness increase within $5 \mathrm{~h}$ during the first step of aging at $760{ }^{\circ} \mathrm{C}$ is also reported (see Fig. 15) in Fisk et al. [79] for Alloy 718 that was hot-rolled and solution-treated at $954{ }^{\circ} \mathrm{C}$ for $1 \mathrm{~h}$ prior to ageing.

An alternative approach to precipitating strengthening phases in HIPed EB-PBF Alloy 718 could be continuous cooling, as mentioned in Section 4.1. Experiments were conducted to evaluate the feasibility of this approach for performing STA through controlled cooling after holding at HIP temperature (see Appendix C for details). Fig. 16 shows the hardness results from the continuous cooling experiments, with pressure (STA was performed inside the HIP vessel directly after the HIP treatment) and without pressure (STA in a heat treatment furnace). The results are in good agreement with those by L. Geng et al. [63]. A detailed microstructure characterization related to the continuous cooling experiments and the correlation with hardness is part of another ongoing study. 
a

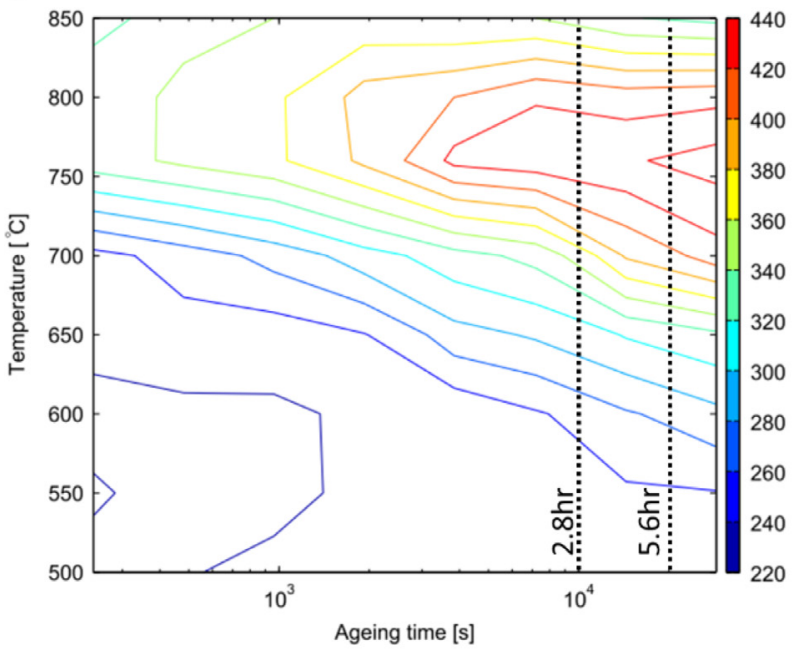

b

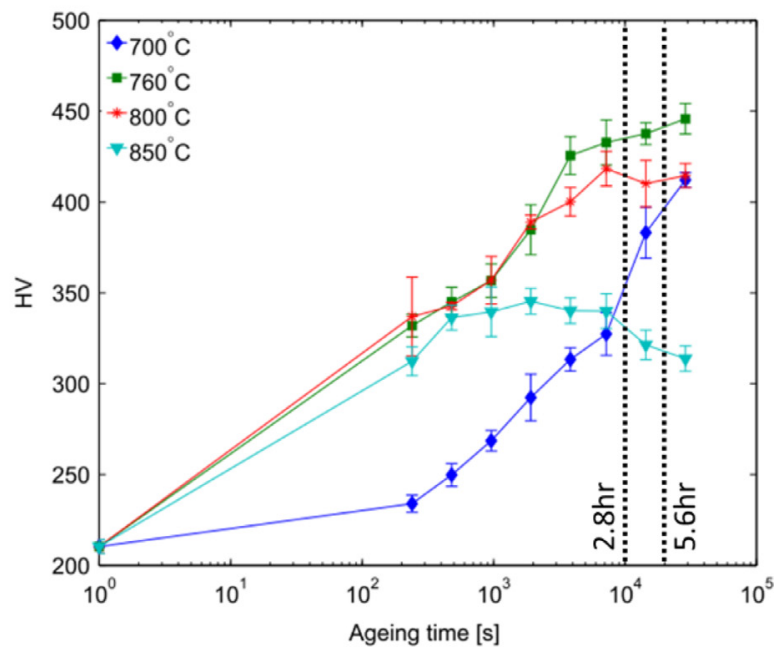

Fig. 15. (a) Contour plot of ageing time, temperature, and microhardness; (b) variation in microhardness with ageing time at four different temperatures for Alloy 718. Taken from [79].

Table 4

Time that Alloy 718 microstructure spent in $\delta$ and $\gamma^{\prime} / \gamma^{\prime \prime}$ precipitation window.

\begin{tabular}{lllll}
\hline Cooling rate $\left({ }^{\circ} \mathrm{C} / \mathrm{min}\right)$ & 0.5 & 2 & 5 & 20 \\
\hline Time $(\mathrm{min})$ spent in direct $\delta$ precipitation window $\left(1020-900^{\circ} \mathrm{C}\right)$ & 240 & 60 & 24 & 6 \\
Time $(\mathrm{min})$ spent in $\gamma^{\prime} / \gamma^{\prime \prime}$ precipitation window $\left(900-600^{\circ} \mathrm{C}\right)$ & 600 & 150 & 60 & 15 \\
Time $(\mathrm{min})$ required to cool down to $500^{\circ} \mathrm{C}$ from $1120^{\circ} \mathrm{C}$ & 1240 & 310 & 124 & 31 \\
\hline
\end{tabular}

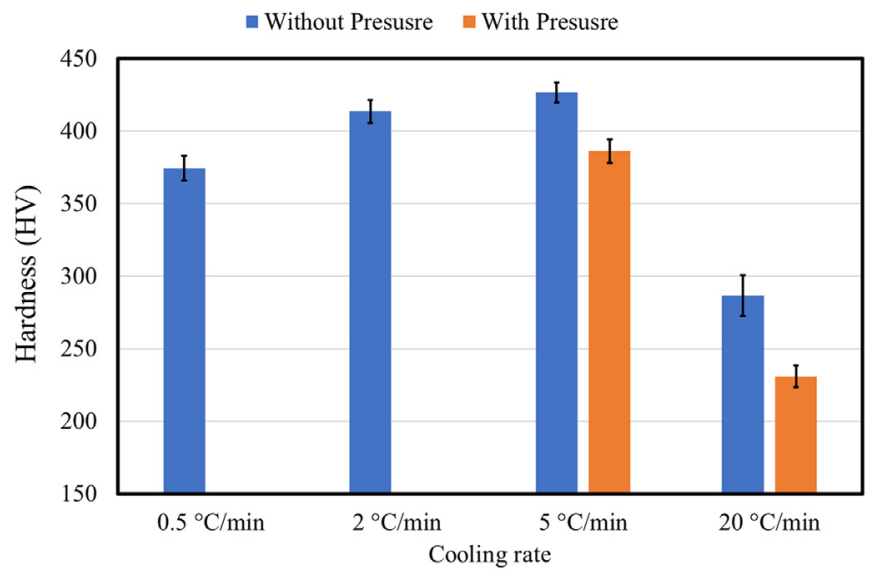

Fig. 16. Effect of cooling rate on hardness of EB-PBF Alloy 718after holding at $1120^{\circ} \mathrm{C}$.

In the continuous cooling experiments by L. Geng et al. [63], the hardness variation was explained by the variation of $\delta$ and $\gamma^{\prime \prime}$ observed in the microstructure under different cooling rates. At $5{ }^{\circ} \mathrm{C} / \mathrm{min}$, a peak in hardness was observed. Below $5{ }^{\circ} \mathrm{C} / \mathrm{min}$, as the cooling rate decreased, hardness dropped gradually. This can be explained by the increase in the $\delta$ phase volume fraction that precipitates with the decrease in the cooling rate. No $\delta$ was observed for cooling rates above $5{ }^{\circ} \mathrm{C} / \mathrm{min}$ [63]. As seen in Table 4 , at $0.5{ }^{\circ} \mathrm{C} / \mathrm{min}$, the microstructure had spent approximately $4 \mathrm{~h}$ in the direct $\delta$ precipitation window; this allows the $\delta$ phase to nucleate and grow, thus reaching a higher volume fraction and consuming more $\mathrm{Nb}$ from the matrix. This lowers the equilibrium volume fraction for $\gamma^{\prime \prime}$ that can precipitate and thereby results in lower hardness. The higher hardness at $5^{\circ} \mathrm{C} / \mathrm{min}$ corresponds to a structure with a high density of fine and discrete $\gamma^{\prime \prime}$ precipitates formed during the time $(\sim 1 \mathrm{~h})$ that the microstructure spent in the $\gamma^{\prime} / \gamma^{\prime \prime}$ precipitation window at a cooling rate of $5^{\circ} \mathrm{C} / \mathrm{min}$. In S. Goel's study [71], it was reported that HIPed Alloy 718 without any other subsequent HT (therefore no $\gamma^{\prime} / \gamma^{\prime \prime}$ ) had a hardness of $\sim 200 \mathrm{HV}$. Comparing this with the hardness resulting from a $20^{\circ} \mathrm{C} / \mathrm{min}$ cooling implies that during the $15 \mathrm{~min}$ strengtheningphase precipitation window, precipitation did occur.

As seen in Fig. 16, the continuous cooling experiments conducted inside the HIP vessel under pressure resulted in lower hardness. This could also be related to the effect of pressure on the phase transformation, as discussed above.

\section{Summary and conclusions}

In this paper, we presented and discussed aspects of phase transformation in Alloy 718 during the L-DED and EB-PBF AM processes and the commonly used subsequent post HIP and HTs. Data gathered from the literature, theoretical principles, and additional modeling results were used in this study. The present discussion demonstrated that the phase transformation in Alloy 718 is complex and influenced by factors such as solidification thermal conditions, the thermal history as well as the composition segregation observed during the process. Therefore, controlling the thermal condition during the AM process is of the utmost importance. In addition to that, the change in local thermodynamics and kinetics of the Alloy 718 due to the local change in composition influence the phase transformation during the standard post HT for the Alloy 718.

Discussion presented in this article reveal that the common HTs originally designed for cast-and-wrought Alloy 718 may not be the optimal solution for additively manufactured Alloy 718 parts. Therefore, focus should be placed on designing new HTs specifically for additively manufactured Alloy 718. In this study, the grain structure changes during HIP and HTs were not discussed in detail. However, in the design of new HTs for AM Alloy 718, the effect of grain structure (morphology, distribution, and texture) changes should also be considered, particularly if 
the HT temperatures are high $\left(>1000{ }^{\circ} \mathrm{C}\right)$, where grain growth can occur. Additive manufacturing allows the production of a wide range of grain microstructures, from columnar to equiaxed grains, in a single part $[1,2,33]$. Consequently, designing HIP and HTs applicable to all these different grain structures will definitely be a challenging task, as these structures tend to behave differently under post-HIP and HT conditions.

Even though LB-PBF was not considered, it is conceivable that the information and discussion provided herein could be used to understand the phase transformation during LB-PBF and the subsequent HIP and HTs. As LB-PBF is a colder process, the discussion given in Section 3 may be a starting point to understand the phase transformation for this process as well. However, owing to the increased cooling rate, the length scale of LB-PBF will be smaller than that of the L-DED process.

In conclusion, we believe that the information and discussion presented in this paper will promote the understanding of the overall process-structure-property relationship in AM of Alloy 718.

\section{Acknowledgements}

The funding from the European Regional Development Fund for project 3Dprint, and from KK Foundation (Stiftelsen för Kunskaps- och Kompetensutveckling) for project SUMAN-Next is also acknowledged. The authors are very grateful to Mr Mats Högström, University West and Mr Johannes Gårdstam, Quintus Technologies AB, Västerås, Sweden for carrying out the continuous cooling experiments.

\section{Declaration of Competing Interest}

None.

\section{Appendix: A}

Modeling the effect of solidification on Alloy 718 conditions using MICRESS

Herein, the MICRESS software package, which is based on the multiphase-field method [80-83], is used to investigate the effect of solidification condition of Laves-phase formation in Alloy 718. The models were set up as follows.

Modeling was performed in 2D. The size of the modelling domain was $80 \mu \mathrm{m} \times 80 \mu \mathrm{m}$ with $0.1 \mu \mathrm{m}$ grid spacing. A constant thermal gradient was applied from top to bottom of the domain. A constant cooling rate was applied to the whole domain. This mimics the moving of the liquidus isotherm from bottom to top in the simulation domain. At the beginning of the simulation, a grain which has almost flat liquid $/ \gamma$ interface with random noise was set at the bottom of the simulation domain. The orientation of this grain was set so that its fast-growth direction is parallel to the applied thermal gradient direction in the domain. This mimics the growth of epitaxial dendrites from a substrate or the re-melted layers. During the simulation, the nucleation of new $\gamma$ grains were set randomly in the liquid. For simplicity, only the liquid $/ \gamma$ interface was modeled as an anisotropic interface having cubic crystal anisotropy. The rest of the simulation parameters, including simplified nominal Alloy 718 composition, nucleation of Laves phase, interfacial energy values, interface thickness, and interfacial stiffness/mobility coefficient for anisotropy were taken from [23]. Thermodynamic and mobility data were taken from the TCNI8 and MOBNI4 databases from Thermo-Calc [84].

The MICRESS model setup we used here is similar to the model setup reported in Nie et al. [30]. However, in Nie et al has used a stochastic modelling approach and modelled the Alloy 718 system as Ni-Nb bi-

$$
\begin{gathered}
\mathrm{G}=1250 \mathrm{~K} / \mathrm{cm} \\
\dot{T}=-4473 \mathrm{~K} / \mathrm{s}
\end{gathered}
$$
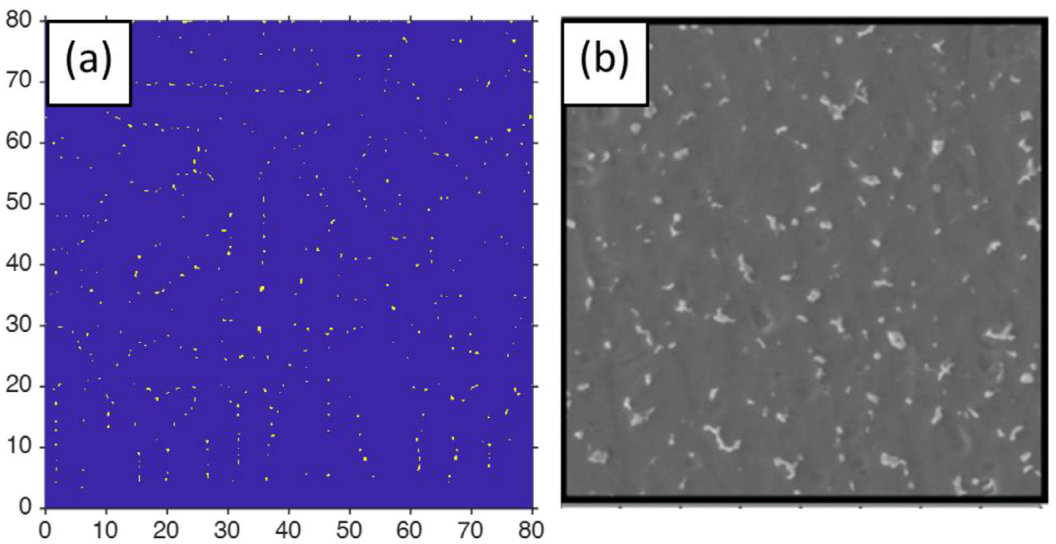

$$
\begin{aligned}
& \mathrm{G}=2375 \mathrm{~K} / \mathrm{cm} \\
& \dot{T}=-1411 \mathrm{~K} / \mathrm{s}
\end{aligned}
$$
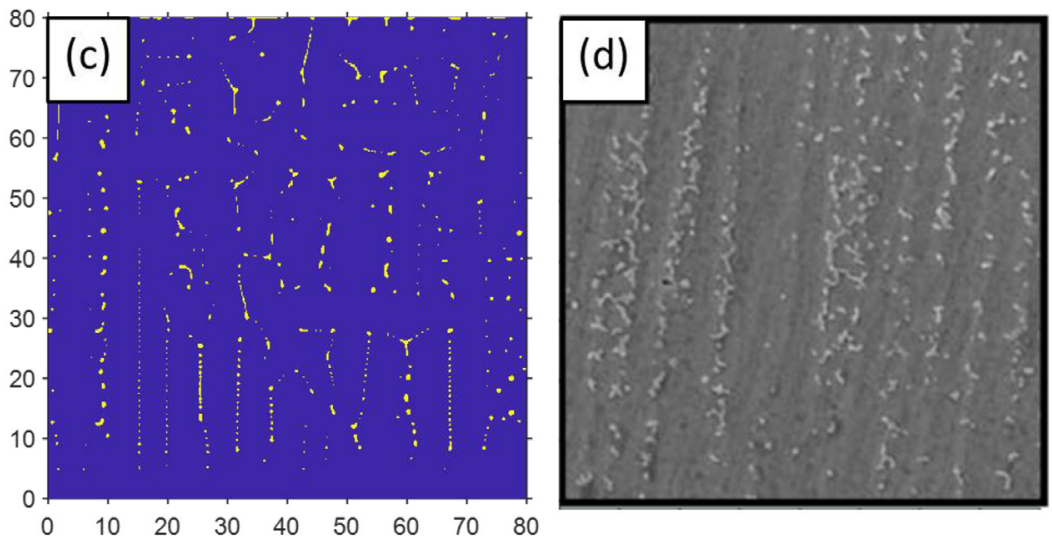

Fig. A1. (a), (c) Predicted morphology of the Laves phase at two different thermal conditions and (b), (d) respective experimentally observed Laves phase morphology in the microstructure (size $80 \mu \mathrm{m} \times 80 \mu \mathrm{m}$ ).

Thermal conditions and the experimentally observed microstructures were taken from Nie et al. [30]. 
nary system without considering the Laves phase formation explicitly. Whereas in our case we have modelled the Alloy 718 as 6 element system (Ni-Cr-Fe-Mo-Nb-Ti) and explicitly modelled the formation of Laves phase in the microstructure. In addition to that, Nie et al. have used fixed orientation for the new $\gamma$ grains that form in the liquid. The model predictions in our current study were also in a better agreement with the experimental observations (see Fig. A1) reported in Nie et al. [30].

\section{Appendix: B}

\section{Direct ageing heat-treatment simulations using MICRESS}

Herein, DA, as per AMS5383, was simulated using MICRESS. The microstructure resulted from the L-DED thermal cycle simulation in [23] was used as the initial starting microstructure. During the simulation, only the nucleation (randomly) of $\gamma^{\prime \prime}$ in the matrix was set for simplicity. The grid resolution of the L-DED simulation was $50 \mu \mathrm{m}$. Therefore, the correct size and morphology of $\gamma^{\prime \prime}$ could not be resolved correctly under this grid resolution. To overcome this, the analytical curvature model $[82,85,86]$ implemented in MICRESS was used. The anisotropy of $\gamma / \gamma^{\prime \prime}$ was neglected, and an isotropic interaction model was adopted. An interfacial energy of $1 \times 10^{-5} \mathrm{~J} / \mathrm{cm}^{2}$ [87] was used. No phase interaction between the Laves phase and $\gamma^{\prime \prime}$ was modeled. The rest of the parameters, including simplified Alloy 718 composition, were taken from [23].

\section{Appendix: C}

\section{Continuous cooling experiments without pressure}

HIPed EB-PBF Alloy 718 samples were used for the continuous cooling experiments. Samples $(17 \mathrm{~mm} \times 15 \mathrm{~mm} \times 55 \mathrm{~mm})$ were printed with an Arcam A2X machine using Arcam Standard parameters. Before the continuous cooling, the samples were again homogenized at $1120^{\circ} \mathrm{C}$ for $1 \mathrm{~h}$. The experiments related to $0.5^{\circ} \mathrm{C} / \mathrm{min}$ and $2^{\circ} \mathrm{C} /$ min cooling rates were conducted using an alumina tube furnace (model R120/500/13, Nabertherm GmbH, Germany) in an inert argon atmosphere. The rest of the cooling rate experiments were conducted using a Gleeble 3800D system (Dynamic Systems Inc, Poestenkill, NY, USA). All the cooling rates were maintained up to $500^{\circ} \mathrm{C}$, and thereafter the samples were quenched to room temperature. The samples were metallographically prepared for hardness evaluation. Hardness measurements were performed using a Shimadzu HMV-2 microhardness tester with $1 \mathrm{~kg}$ load and $15 \mathrm{~s}$ dwell time.

\section{Continuous cooling experiments with pressure}

The continuous cooling rate studies inside the HIP furnace (Model QIH21, Quintus Technologies, Sweden) were performed under pressure. EB-PBF Alloy 718 samples were first HIPed at $1120{ }^{\circ} \mathrm{C} / 100 \mathrm{MPa}$ for $4 \mathrm{~h}$ before being continuously cooled at $5{ }^{\circ} \mathrm{C} / \mathrm{min}$ and $20^{\circ} \mathrm{C} / \mathrm{min}$. However, during cooling, the pressure gradually dropped with temperature to a value of $40 \mathrm{MPa}$. The samples were metallographically prepared for hardness evaluation. Hardness measurements were performed using a Shimadzu HMV-2 microhardness tester with $1 \mathrm{~kg}$ load applied for 15 s.

\section{References}

[1] S.S. Babu, et al., Additive Manufacturing of Nickel SuperAlloy 718 s: Opportunities for Innovation and Challenges Related to Qualification, Metall. Mater. Trans. A 49 (9) (Sep. 2018) 3764-3780.

[2] T. DebRoy, et al., Additive manufacturing of metallic components - Process, structure and properties, Prog. Mater. Sci. 92 (Mar. 2018) 112-224.

[3] M.M. Attallah, R. Jennings, X. Wang, L.N. Carter, Additive manufacturing of Ni-based superAlloy 718 s: The outstanding issues, MRS Bull 41 (10) (2016) 758-764.
[4] S. Sui, et al., The influence of Laves phases on the room temperature tensile properties of Inconel 718 fabricated by powder feeding laser additive manufacturing, Acta Mater 164 (2019) 413-427 February.

[5] M. Anderson, A.-L. Thielin, F. Bridier, P. Bocher, J. Savoie, $\delta$ Phase precipitation in Inconel 718 and associated mechanical properties, Mater. Sci. Eng. A 679 (Jan. 2017) 48-55.

[6] G.A. Knorovsky, M.J. Cieslak, T.J. Headley, A.D. Romig, W.F. Hammetter, INCONEL 718: a solidification diagram, Metall. Trans. A 20 (10) (Oct. 1989) 2149-2158.

[7] R.W. Hayes, Creep Deformation of Inconel Alloy 718 in the $650^{\circ} \mathrm{C}$ To $760^{\circ} \mathrm{C}$, in: SuperAlloy 718 s 718, 625 and Various Derivatives, 1991, 1991, pp. 549-562.

[8] C. Kumara, Microstructure Modelling of Additive Manufacturing of Alloy 718, 2018.

[9] J.F. Radavich, The physical metallurgy of cast and wrought alloy 718, SuperAlloy 718s 718 Metall. Appl. (1989) 229-240.

[10] M. Sundararaman, P. Mukhopadhyay, S. Banerjee, Precipitation of the Delta-Ni3Nb phase in two nickel base superAlloy 718s, Metall. Trans. A 19 (3) (1988) 453-465.

[11] S. Azadian, L.Y. Wei, R. Warren, Delta phase precipitation in inconel 718, Mater. Charact. 53 (1) (2004) 7-16.

[12] T. Antonsson, H. Fredriksson, The effect of cooling rate on the solidification of INCONEL 718, Metall. Mater. Trans. B 36 (1) (Feb. 2005) 85-96.

[13] J.T. Tharappel, J. Babu, Welding processes for Inconel 718- A brief review welding processes for Inconel 718- a brief review, IOP Conf. Series: Materials Science and Engineering, 330, 2018.

[14] D. Deng, R.L. Peng, H. Söderberg, J. Moverare, On the formation of microstructural gradients in a nickel-base superAlloy 718 during electron beam melting, Mater. Des. 160 (2018) 251-261.

[15] Y. Zhang, Z. Li, P. Nie, Y. Wu, Effect of cooling rate on the microstructure of laser-remelted INCONEL 718 coating, Metall. Mater. Trans. A 44 (12) (Dec. 2013) 5513-5521.

[16] J.K. Tien, T. Caulfield, SuperAlloy 718s, supercomposites and superceramics, Academic Press, 1989.

[17] W.M. Haynes, CRC Handbook of Chemistry and Physics - Google Books, 97th ed., CRC Press, 2016.

[18] R. Trivedi, W. Kurz, Solidification microstructures: a conceptual approach, Acta Metall. Mater. 42 (1) (1994) 15-23.

[19] Z. Wang, K. Guan, M. Gao, X. Li, X. Chen, X. Zeng, The microstructure and mechanical properties of deposited-IN718 by selective laser melting, J. Alloy 718s Compd. 513 (2012) 518-523.

[20] D. Deng, R.L. Peng, H. Brodin, J. Moverare, Microstructure and mechanical properties of Inconel 718 produced by selective laser melting: sample orientation dependence and effects of post heat treatments, Mater. Sci. Eng. A 713 (October 2017) 294-306 2018.

[21] S. Ghosh, et al., Single-track melt-pool measurements and microstructures in Inconel 625, Jom (2018) February.

[22] S. Ghosh, M.R. Stoudt, L.E. Levine, J.E. Guyer, Formation of Nb-rich droplets in laser deposited Ni-matrix microstructures, Scr. Mater. 146 (2017) 36-40.

[23] C. Kumara, et al., Microstructure modelling of laser metal powder directed energy deposition of Alloy 718, Addit. Manuf. 25 (2019) 357-364.

[24] C. Kumara, D. Deng, F. Hanning, M. Raanes, J. Moverare, P. Nylén, Predicting the Microstructural Evolution of Electron Beam Melting of Alloy 718with Phase-Field Modeling, Metall. Mater. Trans. A Phys. Metall. Mater. Sci. 50 (5) (2019) 2527-2537.

[25] H. Qi, M. Azer, A. Ritter, Studies of standard heat treatment effects on microstructure and mechanical properties of laser net shape manufactured INCONEL 718, Metall. Mater. Trans. A 40 (10) (Oct. 2009) 2410-2422.

[26] W. Huang, J. Yang, H. Yang, G. Jing, Z. Wang, X. Zeng, Heat treatment of Inconel 718 produced by selective laser melting: Microstructure and mechanical properties, Mater. Sci. Eng. A 750 (2019) 98-107 February.

[27] G.D. Janaki Ram, A. Venugopal Reddy, K. Prasad Rao, G.M. Reddy, J.K. Sarin Sundar, Microstructure and tensile properties of Inconel 718 pulsed Nd-YAG laser welds, J. Mater. Process. Technol. 167 (1) (Aug. 2005) 73-82.

[28] X. Li, et al., Effect of heat treatment on microstructure evolution of Inconel 718 Alloy 718 fabricated by selective laser melting, J. Alloy 718s Compd. 764 (2018) 639-649.

[29] J.J. Schirra, R.H. Caless, R.W. Hatala, The effect of laves phase on the mechanical properties of wrought and cast + HIP Inconel 718, in: SuperAlloy 718s 718, 625 and Various Derivatives, 1991, 1991, pp. 375-388.

[30] P. Nie, O.A. Ojo, Z. Li, Numerical modeling of microstructure evolution during laser additive manufacturing of a nickel-based superAlloy 718, Acta Mater 77 (Sep. 2014) 85-95.

[31] F.D.J. Kurz W., Fundamentals of solidification, 1988, CRC Press, 1998 June 1.

[32] Ø. Grong, Metallurgical modelling of welding, Institute of Materials, 1997.

[33] A.R. Balachandramurthi, J. Olsson, J. Ålgårdh, A. Snis, J. Moverare, R. Pederson, Microstructure tailoring in Electron Beam Powder Bed Fusion additive manufacturing and its potential consequences, Results Mater 1 (2019) 100017 August.

[34] N. Raghavan, et al., Numerical modeling of heat-transfer and the influence of process parameters on tailoring the grain morphology of IN718 in electron beam additive manufacturing, Acta Mater 112 (2016) 303-314

[35] G. Lindwall, et al., Simulation of TTT curves for additively manufactured Inconel 625, Metall. Mater. Trans. A 50 (1) (Jan. 2019) 457-467.

[36] Y. Tian, et al., Rationalization of microstructure heterogeneity in INCONEL 718 builds made by the direct laser additive manufacturing process, Metall. Mater. Trans. A 45 (10) (Sep. 2014) 4470-4483.

[37] R.G. Carlson, J.F. Radavich, Microstructural characterization of cast 718, SuperAlloy 718s 718 Metall. Appl. (1989) 79-95.

[38] A. Segerstark, J. Andersson, L. Svensson, O. Ojo, Microstructural characterization of laser metal powder deposited Alloy 718, Mater. Charact. 142 (Aug. 2018) 550-559 June. 
[39] A. Segerstark, J. Andersson, L. Svensson, Evaluation of a temperature measurement method developed for laser metal deposition, Sci. Technol. Weld. Join. 22 (1) (Jan. 2017) 1-6.

[40] Z. Li, J. Chen, S. Sui, C. Zhong, X. Lu, X. Lin, The microstructure evolution and tensile properties of Inconel 718 fabricated by high-deposition-rate laser directed energy deposition, Addit. Manuf. 31 (2020) 100941 November 2019.

[41] X. Zhao, J. Chen, X. Lin, W. Huang, Study on microstructure and mechanical properties of laser rapid forming Inconel 718, Mater. Sci. Eng. A 478 (1-2) (Apr. 2008) $119-124$.

[42] Y.-N. Zhang, X. Cao, P. Wanjara, M. Medraj, Tensile properties of laser additive manufactured Inconel 718 using filler wire, J. Mater. Res. 29 (17) (Sep. 2014) 2006-2020.

[43] C. Zhong, A. Gasser, J. Kittel, J. Fu, Y. Ding, R. Poprawe, Microstructures and tensile properties of Inconel 718 formed by high deposition-rate laser metal deposition, J. Laser Appl. 28 (2) (2016) 022010.

[44] Y. Zhang, L. Yang, T. Chen, W. Zhang, X. Huang, J. Dai, Investigation on the optimized heat treatment procedure for laser fabricated IN718 Alloy 718, Opt. Laser Technol. 97 (2017) 172-179 October.

[45] L. Zhu, Z. Xu, Y. Gu, Effect of laser power on the microstructure and mechanical properties of heat treated Inconel 718 superAlloy 718 by laser solid forming, J. Alloy 718s Compd. 746 (2018) 159-167.

[46] S. Sui, C. Zhong, J. Chen, A. Gasser, W. Huang, J.H. Schleifenbaum, Influence of solution heat treatment on microstructure and tensile properties of Inconel 718 formed by high-deposition-rate laser metal deposition, J. Alloy 718s Compd. 740 (2018) 389-399.

[47] S. Sui, et al., Microstructures and stress rupture properties of pulse laser repaired Inconel 718 superAlloy 718 after different heat treatments, J. Alloy 718s Compd. 770 (2019) 125-135.

[48] J.F. Muller, M.J. Donachie, The effects of solution and intermediate heat treatments on the notch-rupture behavior of Inconel 718, Metall. Mater. Trans. A 6 (12) (1975) 2221-2227.

[49] G. Sjoberg, N.G. Ingesten, R.G. Carlson, Grain boundary $\delta$-phase morphologies, carbides and notch rupture sensitivity of cast alloy 718, in: SuperAlloy 718s 718, 625, 706 and Derivatives, 1991, 1991, pp. 603-620.

[50] D. Cai, W. Zhang, P. Nie, W. Liu, M. Yao, Dissolution kinetics of $\delta$ phase and its influence on the notch sensitivity of Inconel 718, Mater. Charact. 58 (3) (2007) $220-225$.

[51] S. Sui, et al., Microstructures and stress rupture properties of pulse laser repaired Inconel 718 superAlloy 718 after different heat treatments, J. Alloy 718s Compd. 770 (2019) 125-135.

[52] S. Sui, J. Chen, Z. Li, H. Li, X. Zhao, H. Tan, Investigation of dissolution behavior of Laves phase in Inconel 718 fabricated by laser directed energy deposition, Addit. Manuf. (2020) 101055 January.

[53] L. Zhu, Z. Xu, Y. Gu, Effect of laser power on the microstructure and mechanical properties of heat treated Inconel 718 superAlloy 718 by laser solid forming, J. Alloy 718s Compd. 746 (2018) 159-167.

[54] Porter D A, E.K. E, M.Y. SHERIF, Phase Transformations in metals and Alloy 718s, CRC Press, 2009.

[55] M. Sundararaman, N. Sachin, B.S. Jung, V. Amit, P. Bhaskar, R. Kishore, Evolution of $\delta$ phase microstructure in Alloy 718, 7th Int. Symp. SuperAlloy 718s 718 Deriv. (2010) 737-750.

[56] F. Theska, et al., On the early stages of precipitation during direct ageing of Alloy 718, Acta Mater 188 (2020) 492-503.

[57] R.R. Dehoff, et al., Site specific control of crystallographic grain orientation through electron beam additive manufacturing, Mater. Sci. Technol. 31 (8) (2015) 931-938.

[58] M.M. Kirka, et al., Strategy for Texture Management in Metals Additive Manufacturing, JOM 69 (3) (. 2017) 523-531.

[59] W.J. SAMES, Additive manufacturing of inconel 718 using electron beam melting: processing, post-processing, \& mechanical properties, A\&M University, Texas, 2015.

[60] M.M. Kirka, K.A. Unocic, N. Raghavan, F. Medina, R.R. Dehoff, S.S. Babu, Microstructure development in electron beam-melted inconel 718 and associated tensile properties, JOM 68 (3) (. 2016) 1012-1020.

[61] A.R. Balachandramurthi, J. Moverare, S. Mahade, R. Pederson, Additive manufacturing of Alloy 718via electron beam melting: Effect of post-treatment on the microstructure and the mechanical properties, Materials (Basel) 12 (1) (2018).

[62] S. Goel, M. Ahlfors, F. Bahbou, S. Joshi, Effect of different post-treatments on the microstructure of EBM-built Alloy 718, J. Mater. Eng. Perform. 28 (2) (2019) 673680.
[63] L. Geng, Y. Na, N.-K. Park, Continuous cooling transformation behavior of Alloy 718, Mater. Lett. 30 (5-6) (1997) 401-405.

[64] W.J. Sames, F.A. List, S. Pannala, R.R. Dehoff, S.S. Babu, The metallurgy and processing science of metal additive manufacturing, Int. Mater. Rev. 6608 (2016) 1-46 March.

[65] ASTM, Standard Specification for Additive Manufacturing Nickel Alloy 718 (UNS N07718) with Powder Bed Fusion F3055-14a, ASTM International, West Conshohocken, PA, 2014 www.astm.org.

[66] A.R. Balachandramurthi, J. Moverare, N. Dixit, R. Pederson, Influence of defects and as-built surface roughness on fatigue properties of additively manufactured Alloy 718, Mater. Sci. Eng. A 735 (2018) 463-474 August.

[67] S. Goel, J. Olsson, M. Ahlfors, U. Klement, S. Joshi, The effect of location and post-treatment on the microstructure of EBM-built Alloy 718, in: Proceedings of the 9th International Symposium on SuperAlloy 718\& Derivatives: Energy, Aerospace, and Industrial Applications, 2018, 2018, pp. 115-129. June.

[68] M.M. Kirka, F. Medina, R. Dehoff, A. Okello, Mechanical behavior of post-processed Inconel 718 manufactured through the electron beam melting process, Mater. Sci. Eng. A (2016) 1-9.

[69] S. Goel, A. Sittiho, I. Charit, U. Klement, S. Joshi, Effect of post-treatments under hot isostatic pressure on microstructural characteristics of EBM-built Alloy 718, Addit. Manuf. 28 (2019) 727-737 June.

[70] D. Deng, J. Moverare, R.L. Peng, H. Söderberg, Microstructure and anisotropic mechanical properties of EBM manufactured Inconel 718 and effects of post heat treatments, Mater. Sci. Eng. A 693 (2017) 151-163 December 2016.

[71] S. Goel, Post-treatment of Alloy 718produced by electron beam melting Licentiate Thesis, University West, 2019.

[72] P. Nandwana, M. Kirka, A. Okello, R. Dehoff, Electron beam melting of Inconel 718: effects of processing and post-processing, Mater. Sci. Technol. (United Kingdom) 34 (5) (2018) 612-619.

[73] K.A. Unocic, L.M. Kolbus, R.R. Dehoff, S.N. Dryepondt, B.A. Pint, High-Temperature performance of UNS N07718 processed by additive manufacturing, corrosion, 2014, 2014 November 2015.

[74] SAE, AMS5383E-Nickel Alloy 718, Corrosion and Heat-Resistant, Investment Castings, 2012.

[75] ASTM, ASTM 2774A - Heat Treatment Wrought Nickel Alloy 718 and Cobalt Alloy 718 Parts AMS, 2011.

[76] A. Strondl et al., "Microstructure and mechanical properties of nickel based superAlloy 718 IN718 produced by rapid prototyping with electron beam melting (EBM) Microstructure and mechanical properties of nickel based superAlloy 718 IN718 produced by rapid prototyping with electro," vol. 0836, 2013.

[77] A. Chamanfar, L. Sarrat, M. Jahazi, M. Asadi, A. Weck, A.K. Koul, Microstructural characteristics of forged and heat treated Inconel-718 disks, Mater. Des. 52 (2013) 791-800.

[78] E. Zaninelli, Effects of post-processing on EBM fabricated Inconel 718 Master Thesis, Università degli studi di Modena e Reggio Emilia, 2018.

[79] M. Fisk, J. Andersson, R. du Rietz, S. Haas, S. Hall, Precipitate evolution in the early stages of ageing in Inconel 718 investigated using small-angle x-ray scattering, Mater. Sci. Eng. A 612 (2014) 202-207.

[80] I. Steinbach, et al., A phase field concept for multiphase systems, Phys. D Nonlinear Phenom. 94 (3) (Jul. 1996) 135-147.

[81] J. Eiken, B. Böttger, I. Steinbach, Multiphase-field approach for multicomponent Alloy 718s with extrapolation scheme for numerical application, Phys. Rev. E 73 (6) (Jun. 2006) 066122.

[82] B. Böttger, J. Eiken, I. Steinbach, Phase field simulation of equiaxed solidification in technical Alloy 718s, Acta Mater 54 (10) (2006) 2697-2704.

[83] J. Eiken, A phase-field model for technical Alloy 718 solidification, Shaker Verlag GmbH, Germany, 2010.

[84] "Thermo-Calc Software." [Online]. Available: http://www.thermocalc.com/. [Accessed: 25-May- 2018].

[85] B. Böttger, M. Apel, B. Laux, S. Piegert, Detached melt nucleation during diffusion brazing of a technical Ni-based superAlloy 718: A phase-field study, IOP Conf. Ser. Mater. Sci. Eng. 84 (1) (2015).

[86] B. Böttger, M. Apel, B. Daniels, L. Dankl, T. Göhler, T. Jokisch, Systematic Phasefield study on microstructure formation during brazing of Mar-M247 with a Si-Based AMS4782 Filler, Metall. Mater. Trans. A (2019).

[87] N. Zhou, et al., Computer simulation of phase transformation and plastic deformation in IN718 superAlloy 718: Microstructural evolution during precipitation, Acta Mater 65 (Feb. 2014) 270-286. 